Prepared for the U.S. Department of Energy

under Contract DE-AC05-76RL01830

\title{
Investigation of CTBT OSI Radionuclide Techniques at the Diluted WATERS Nuclear Test Site
}

$\begin{array}{ll}\text { J Baciak } & \text { EA Lepel } \\ \text { BD Milbrath } & \text { HA Seifert } \\ \text { RS Detwiler } & \text { D Emer } \\ \text { RR Kirkham } & \text { M Floyd }^{1} \\ \text { M Keillor } & \end{array}$

November 2012

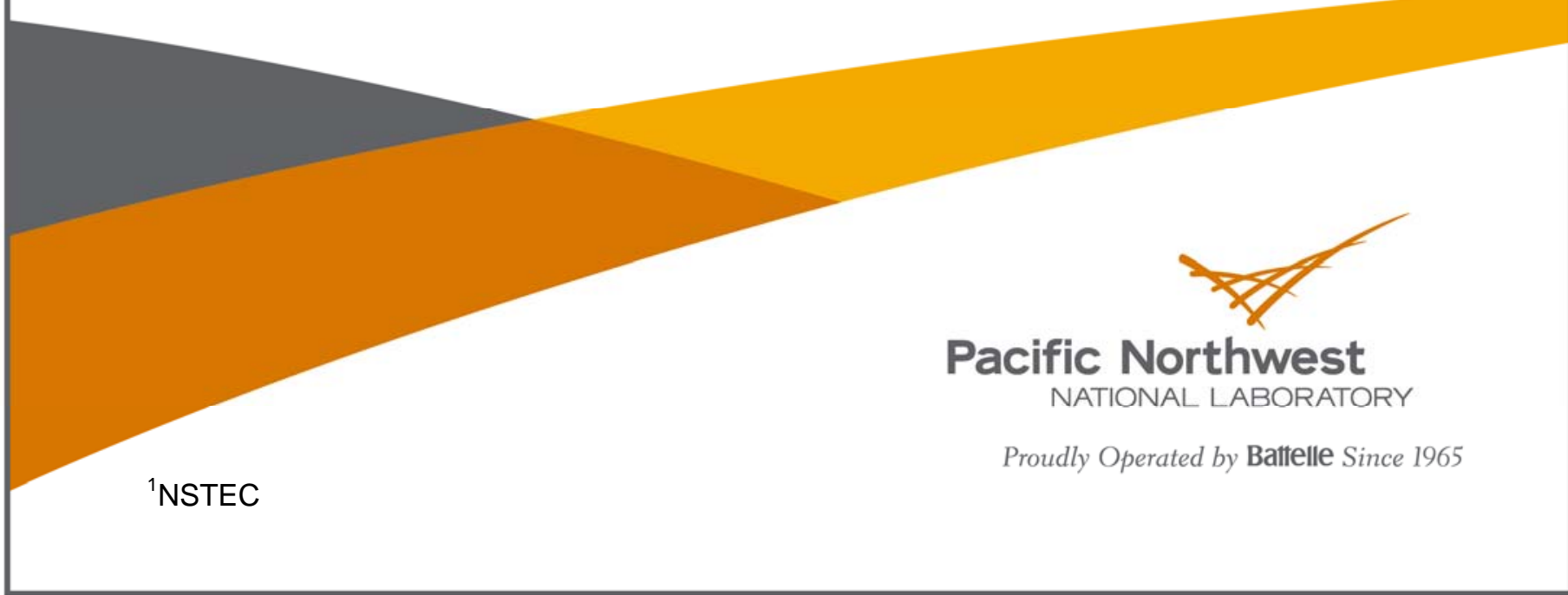




\title{
DISCLAIMER
}

This report was prepared as an account of work sponsored by an agency of the United States Government. Neither the United States Government nor any agency thereof, nor Battelle Memorial Institute, nor any of their employees, makes any warranty, express or implied, or assumes any legal liability or responsibility for the accuracy, completeness, or usefulness of any information, apparatus, product, or process disclosed, or represents that its use would not infringe privately owned rights. Reference herein to any specific commercial product, process, or service by trade name, trademark, manufacturer, or otherwise does not necessarily constitute or imply its endorsement, recommendation, or favoring by the United States Government or any agency thereof, or Battelle Memorial Institute. The views and opinions of authors expressed herein do not necessarily state or reflect those of the United States Government or any agency thereof.

\author{
PACIFIC NORTHWEST NATIONAL LABORATORY \\ operated by \\ BATTELLE \\ for the \\ UNITED STATES DEPARTMENT OF ENERGY \\ under Contract DE-AC05-76RL01830 \\ Printed in the United States of America \\ Available to DOE and DOE contractors from the \\ Office of Scientific and Technical Information, \\ P.O. Box 62, Oak Ridge, TN 37831-0062; \\ ph: (865) 576-8401 \\ fax: $(865)$ 576-5728 \\ email: reports@adonis.osti.gov \\ Available to the public from the National Technical Information Service \\ 5301 Shawnee Rd., Alexandria, VA 22312 \\ ph: (800) 553-NTIS (6847) \\ email: orders@ntis.gov <http://www.ntis.gov/about/form.aspx> \\ Online ordering: http://www.ntis.gov
}




\title{
Investigation of CTBT OSI Radionuclide Techniques at the Diluted WATERs Nuclear Test Site
}

\author{
J Baciak \\ EA Lepel \\ BD Milbrath \\ HA Seifert \\ RS Detwiler \\ D Emer ${ }^{1}$ \\ RR Kirkham \\ M Floyd $^{1}$ \\ M Keillor
}

November 2012

Prepared for

the U.S. Department of Energy under Contract DE-AC05-76RL01830

Pacific Northwest National Laboratory

Richland, Washington 99352

${ }^{1}$ NSTEC 



\section{Executive Summary}

Under the Comprehensive Nuclear-Test-Ban Treaty (CTBT), a verification regime that includes the ability to conduct an On-Site Inspection (OSI) will be established. The Treaty allows for an OSI to include many techniques, including the radionuclide techniques of gamma radiation surveying and spectrometry and environmental sampling and analysis. Such radioactivity detection techniques can provide the "smoking gun" evidence that a nuclear test has occurred through the detection and quantification of indicative recent fission products. An OSI faces restrictions in time and manpower, as dictated by the Treaty; not to mention possible logistics difficulties due to the location and climate of the suspected explosion site. It is thus necessary to have a good understanding of the possible source term an OSI will encounter and the proper techniques that will be necessary for an effective OSI regime.

One of the challenges during an OSI is to locate radioactive debris that has escaped an underground nuclear explosion (UNE) and settled on the surface near and downwind of ground zero. To support the understanding and selection of sampling and survey techniques for use in an OSI, we are currently designing an experiment, the Particulate Release Experiment (PRex), to simulate a small-scale vent from an underground nuclear explosion. PRex will occur at the Nevada National Security Site (NNSS). The project is conducted under the National Center for Nuclear Security (NCNS) funded by the National Nuclear Security Agency (NNSA). Prior to the release experiment, scheduled for Spring of 2013, the project scheduled a number of activities at the NNSS to prepare for the release experiment as well as to utilize the nuclear testing past of the NNSS for the development of OSI techniques for CTBT. One such activity — the focus of this report — was a survey and sampling campaign at the site of an old UNE that vented: DILUTED WATERS.

Activities at DILUTED WATERS included vehicle-based survey, in situ measurements with high-purity germanium (HPGe) and hand-held $\mathrm{LaBr}_{3}$ systems, soil sampling with a variety of tools, and laboratory gamma spectrometric analysis of those samples. A further benefit of the measurement campaign was to gain familiarity with the many logistical aspects of performing radiological field work at NNSS ahead of the PRex.

Many practical lessons concerning the proper methodologies and logistics of using the surveying and sampling equipment were noted. These Lessons Learned are compiled together in Appendix A. The vehicle-based survey was successful in that it found a previously unknown hotspot (determined to be ${ }^{232} \mathrm{Th}$ ) while it demonstrated that a better method for keeping a serpentine track without staking was needed. Some of the soil sampling equipment was found to be impractical for the application, though core sampling would not be the correct way to take soil samples for a fresh vent deposit (as opposed to an old site like DiLUTED WATERS). Due to the site's age, ${ }^{137}$ Cs was the only fission radioisotope identified, though others were searched for. While not enough samples were taken and analyzed to definitively link the ${ }^{137}$ Cs to DILUTED WATERS as opposed to other NNSS activities, results were consistent with the historical DILUTED WATERS plume. MDAs were compared for soil sampling and in situ measurements. 



\section{Acronyms and Abbreviations}

\begin{tabular}{|c|c|}
\hline СТВT(O) & Comprehensive Nuclear-Test-Ban Treaty (Organization) \\
\hline OSI & On-site inspection \\
\hline PNNL & Pacific Northwest National Laboratory \\
\hline UNE & Underground nuclear explosion \\
\hline NNSA & U.S. National Nuclear Security Agency \\
\hline PRex & Particulate Release Experiment \\
\hline NNSS & Nevada National Security Site \\
\hline NCNS & National Center for Nuclear Security \\
\hline HPGe & High-purity germanium \\
\hline MDA & Minimum detectable activity \\
\hline GPS & Global Positioning System \\
\hline LLNL & Lawrence Livermore National Laboratory \\
\hline DoD & U.S. Department of Defense \\
\hline SGZ & Surface ground-zero (coordinates) \\
\hline LOS & Line-of-sight \\
\hline RAM & Radiation activity monitors \\
\hline NPTEC & Nonproliferation Test and Evaluation Complex \\
\hline ATV & All-terrain vehicle \\
\hline DU & Depleted uranium \\
\hline
\end{tabular}

NSCRAD Nuisance-rejection Spectral Comparison Ratio Anomaly Detection 


\section{Contents}

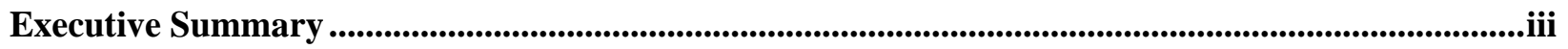

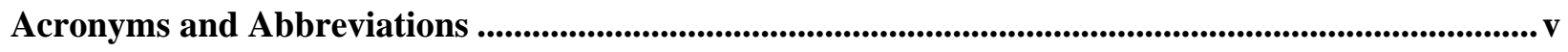

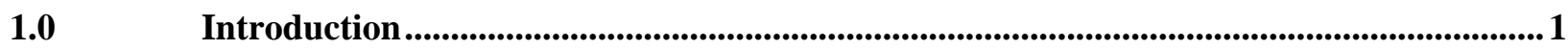

$2.0 \quad$ Description of the DILUTED WATERS Site ..................................................................

B.0 Dates and Schedule of Activities at DILUTED WATERS ...................................................5

4.0 Vehicle-based Survey at DILUTED WATERS..........................................................................

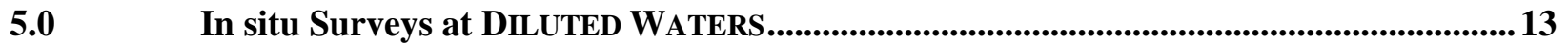

6.0 Environmental Sampling at DILUTED WATERS ...................................................... 14

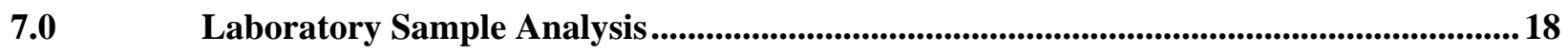

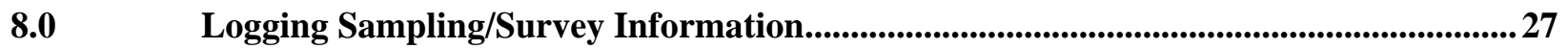

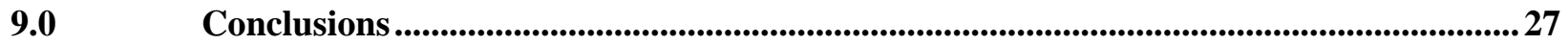

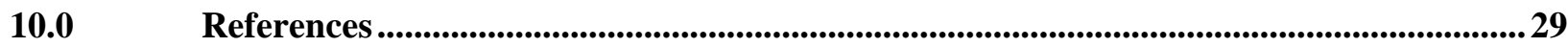

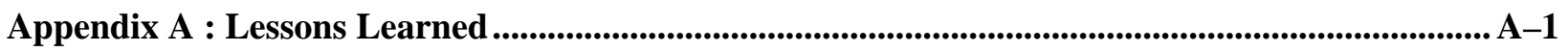




\section{Figures}

Figure 1: Various photographs of the DILUTED WATERS subsidence crater and surrounding area..3

Figure 2: Google Earth aerial photos of the DILUTED WATERS site and surrounding area. (a) The area outlined in blue was the predetermined sampling area. (b) The areas outlined in white and red were the survey areas. Each area has its own distinct survey plan. Up is due north.

Figure 3: Conduct of vehicle surveys with RSI detector

Figure 4: Overlay of the two GPS locators (one from the RSI system, one high-accuracy handheld). The multi-colored points are from the RSI system, and also show the count rate at that particular location. The darker points are from the high-accuracy handheld and closely match the RSI GPS. The purple line is not relevant to the discussion.

Figure 5: RSI system count rate during the 50-m spacing run. The spike was from a previously unidentified ground hotspot near the plane crash site near DILUTED WATERS.

Figure 6: Background-subtracted long-dwell ( $\sim 5.5$ minutes) spectrum from the RSI detector at the site of the hotspot in the DILUTED WATERS survey area. The peaks in the spectrum are associated with the decay of ${ }^{232} \mathrm{Th}$.

Figure 7: NSCRAD representation of the recorded radiation signature from the RSI detector. The data reconstructed in the figure is from the 50 -m spacing survey.

Figure 8: Two-dimensional representation of the NSCRAD results shown in Figure 7. An important feature to note is the noise located in the lower section of the graph. This was caused by poor selection of background and also due to some variation of count rate in the first serpentine line (seen as the depression in count rate in Figure 5). Improvements in NSCRAD settings and background selection should improve the results without disrupting the detection of the hotspot.

Figure 9: Sampling area for DILUTED WATERS showing sampling locations 15

Figure 10: Soil sampling equipment used. Top Left: Lock N' Load soil sampling system. Top Right: Auger tool for breaking up surface if needed. Bottom: Core sampler. The plastic liner is inserted into the metal cylinder and then attached to the long handle. The plastic liner is capped and taped when removed.

Figure 11: Laboratory analysis spectrum from sample 19 showing excess of ${ }^{232}$ Th daughters and indication of DU through the $1001-\mathrm{keV}^{234 \mathrm{~m}} \mathrm{~Pa}$ line

Figure 12: HPGe in situ spectrum from the location of sample 19 showing excess of ${ }^{232} \mathrm{Th}$ daughters and indication of DU through the $1001-\mathrm{keV}^{234 \mathrm{~m}} \mathrm{~Pa}$ line

Figure 13: $\mathrm{LaBr}_{3}$ Hand-held spectrum form location 19 showing excess ${ }^{232}$ Th daughters 
PNNL-22494

Figure 14: Sample Locations at DILUTED WATERS and relative ${ }^{137}$ Cs content (normalized to content of sample 3).

\section{Tables}

Table 1: Corner Coordinates for the Three Survey and Sampling Areas.......................................4

Table 2: Basic schedule for DILUTED WATERS Sampling and Survey Activities...........................5

Table 3: Fixed Sample Locations for DILUTED WATERS ........................................................15

Table 4: Summary of Samples Analyzed and Complementary Measurements .............................19

Table 5: Summary of Sample Laboratory Analysis Results ...................................................20

Table 6: MDA Comparisons between Screening Methods for ${ }^{137} \mathrm{Cs}$........................................25

Table 7: Average NORM content for Nominal Sample sizes ....................................................26 


\subsection{Introduction}

Under the Comprehensive Nuclear-Test-Ban Treaty (CTBT) (adopted by the UN and open for signature and ratification or accession by States Parties, but not yet entered into force), a verification regime that includes the ability to conduct an On-Site Inspection (OSI) will be established. The sole purpose of such an OSI is to determine whether a nuclear explosion has occurred in violation of the Treaty and gather facts that might assist in identifying any possible violator. The Treaty allows for an OSI to include many techniques including the radionuclide techniques of gamma radiation surveying and spectrometry (from above, at, or below the surface) and environmental sampling and analysis (of solids, liquids, and gases from above, at, or below the surface). Radioactivity detection techniques can provide the "smoking gun" evidence that a nuclear test has occurred through the detection and quantification of indicative recent fission products. While it may be trivial in some scenarios (such as an above-ground nuclear explosion) for an OSI to obtain such radiological evidence, this will not always be the case. Adding to this, an OSI faces restrictions in time and manpower dictated by the Treaty; not to mention possible logistics difficulties due to the location and climate of the suspected explosion site. It is thus necessary to have a good understanding of the possible source term an OSI will encounter and the proper techniques that will be necessary for an effective OSI regime.

One of the challenges during an OSI is to locate radioactive debris that has escaped an underground nuclear explosion (UNE) and settled on the surface near and downwind of ground zero. To support the understanding and selection of sampling and survey techniques for use in an OSI, we are currently designing an experiment, the Particulate Release Experiment (PRex), to simulate a small-scale vent from a UNE. This initial test will use short-lived radioisotopes to provide a realistic ground deposition pattern from a single vent location. The experiment will afford an opportunity to investigate aerial and ground survey techniques, sampling and OSI base of operations laboratory measurements, and the associated minimum detectable concentrations. The work is also being planned so as to provide data useful in developing and benchmarking local atmospheric transport models and in the development of radiation anomaly detection and information barrier algorithms.

PRex will occur at the Nevada Nuclear Security Site (NNSS). The project is conducted under the National Center for Nuclear Security (NCNS), funded by the National Nuclear Security Agency (NNSA). It is one of many projects designed to utilize the capabilities of the NNSS to study technical issues related to nuclear weapons treaties. Prior to the release experiment, scheduled for Spring of 2013, the project scheduled a number of activities at the NNSS to prepare for the release experiment and to utilize the nuclear testing past of the NNSS for the development of OSI techniques for CTBT. One such activitythe focus of this report-was a survey and sampling campaign at the site of an old UNE that vented: DILUTED WATERS. This survey and sampling campaign occurred in March 2012.

The objective of the survey and sampling activities at the old DILUTED WATERS site was to test a subset of equipment and sample collection methodologies to gain insight into best practices for sampling and survey of a nuclear test site within an OSI framework. A further objective was to determine whether there might be useful residual data at old test sites relevant to the development of OSI techniques. In particular, the samples and data obtained during the activities at DILUTED WATERS were to be used to

- determine the effectiveness of different sampling techniques and equipment 
- test many logistical aspects of performing radiological field work at NNSS ahead of the PRex experiment, such as shipping samples from NNSS to PNNL and working in areas of old test sites

- perform an analysis of ground survey using a single RSI log

- test different in-situ sampling equipment

- compare results from previous reports and historical documents associated with the Diluted Waters test

Included throughout this document are Lessons Learned, comprised of our observations during the course of sampling and surveying relevant to our work at NNSS and conducting an OSI in general. While often they are not particularly scientific or technical, they nonetheless offer good advice on the many little things that could trip up the conduct of an OSI.

\subsection{Description of the DiLUTED WATERS Site}

The DILUTED WATERS nuclear test was a LLNL/DOD underground vertical shaft detonation with a yield of less than $20 \mathrm{kT}$. DiLUTED WATERS was a weapons-effect test and was conducted on June 16, 1965 at 0930 local time. The DILUTED WATERS site is located in Area 5 of NNSS (specifically U5b). The surface ground zero (SGZ) coordinates for the site are approximately $36.818^{\circ} \mathrm{N}, 115.957^{\circ} \mathrm{W}$. Venting began almost immediately due to a stemming failure, and continued for approximately 20 minutes, resulting in a gross fission product release. The test release activity at +12 hours was calculated to be $3.0 \times 10^{4} \mathrm{Ci}$. Radioisotopes detected at the time of the release were: kryptons, ${ }^{99} \mathrm{Mo},{ }^{103} \mathrm{Ru},{ }^{105} \mathrm{Ru},{ }^{131} \mathrm{I}$, ${ }^{133} \mathrm{I},{ }^{134} \mathrm{I},{ }^{135} \mathrm{I},{ }^{132} \mathrm{Te},{ }^{135} \mathrm{Xe},{ }^{138} \mathrm{Cs},{ }^{139} \mathrm{Ba},{ }^{140} \mathrm{Ba} / \mathrm{La}$, and ${ }^{141} \mathrm{Ce}$. The iodines were found in their proper ratio for mixed fission products and comprised $34 \%$ of the total activity released, indicating the release was fractionated toward the gaseous elements. Radioactivity from the test was detected offsite, the cloud having traveled in a northeasterly direction (U.S. DOE 2000; Schoengold et al. 1996; Nelson Jr. 1965).

The release began through the line-of-sight (LOS) pipe about one second after the test and decreased in intensity until nearly stopping after 15 to 20 seconds. At this time, gas began to be forcibly ejected at the base of the LOS tower. This release was stronger than the first and continued until 4.2 minutes after the test when the surface subsided, stemming the release (U.S. Defense Nuclear Agency 1984). The resulting crater was $97 \mathrm{ft}$ deep. Remote radiation activity monitors (RAMs) were located around DILUTED WATERS at SGZ, 100, 500, 1000, and $2000 \mathrm{ft}$. These recorded their strongest readings for the initial one minute after the test. Initially, the highest readings were observed to the northeast and northwest for the RAMs at $100 \mathrm{ft}$, to the northwest for the RAMs at 500 and $1000 \mathrm{ft}$, and to the northeast for the RAMs at $2000 \mathrm{ft}$. The initial gamma dose reading of the SGZ RAM and those at $100 \mathrm{ft}$ northeast and northwest were several million milliRoentgen per hour, and no readings exist after two minutes (possibly due to the crater collapse). The RAM measurements decreased rapidly with a small rebound in intensity occurring at approximately 16 minutes (a few minutes later for the $2000 \mathrm{ft}$ RAMs) in all but the first (northeast) quadrant, before the continued decrease. Readings after 1 hour ranged from 300-3000 mR/hr (Mullen 1969).

The DiLUTED WATERS site is near the currently-utilized Nonproliferation Test and Evaluation Complex (NPTEC), and coordination was required to assure unrestricted access during the proposed activity dates. Pictures of the crater site are shown in Figure 1. The general topography of the Frenchman Flat basin (including the DiLUTED WATERS site) is quite flat with low density sagebrush and light desert grass as the 
only vegetation. The soil itself is mainly sandy with small stones. The subsidence crater of DILUTED WATERS is gently sloped on the south side of the crater. The crater itself is accessible by either foot or off-road vehicle (such as an all-terrain vehicle (ATV)). Thus, it is possible to perform sampling and survey activities within the crater. Currently, there are no roped-off radiation or un-subsided crater zones, and the entire crater area is accessible with work authorization.
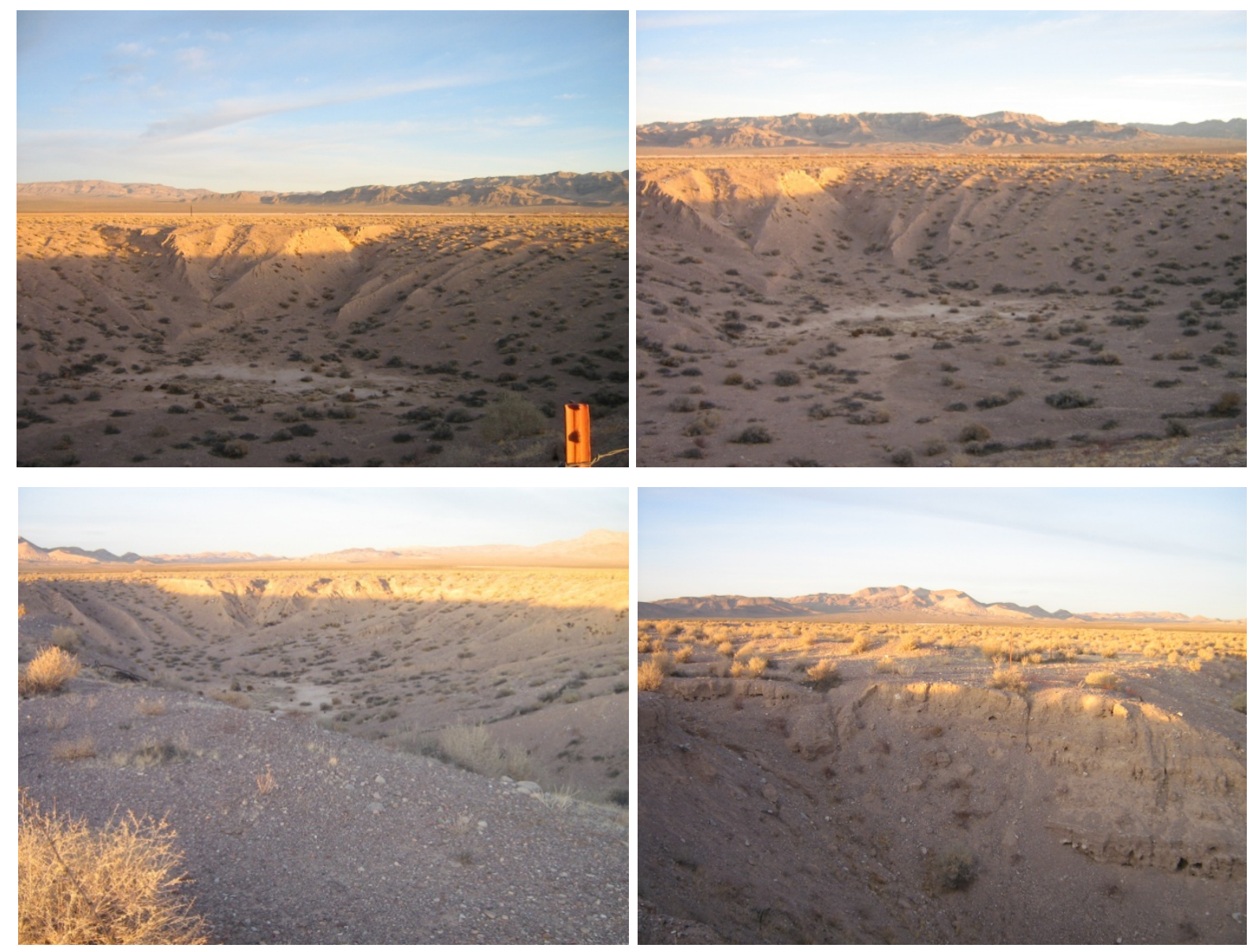

Figure 1: Various photographs of the DILUTED WATERS subsidence crater and surrounding area

For the activities at DILUTED WATERS, we performed sampling and surveys in and around the crater and to the north-northeast of the crater (in the general direction of the plume). Figure 2 below shows an aerial view of the site, along with the sampling area (a) and survey areas (b). The sampling area (outlined in blue) encompasses a $200 \times 200 \mathrm{~m}^{2}$ area and includes the northern half of the crater and area just north of the crater. The survey areas are marked in red and white in Figure 2(b). We had two distinct survey activities. One (red) was for surveying the crater and represents a $225 \times 200 \mathrm{~m}^{2}$ area, while the second (white) was a $500 \times 500 \mathrm{~m}^{2}$ area in the general direction of the plume from the shot. Surveys are discussed in Sections 5.0 and 6.0, while Sections 7.0 and 8.0 discuss the sampling and laboratory analysis activities. 


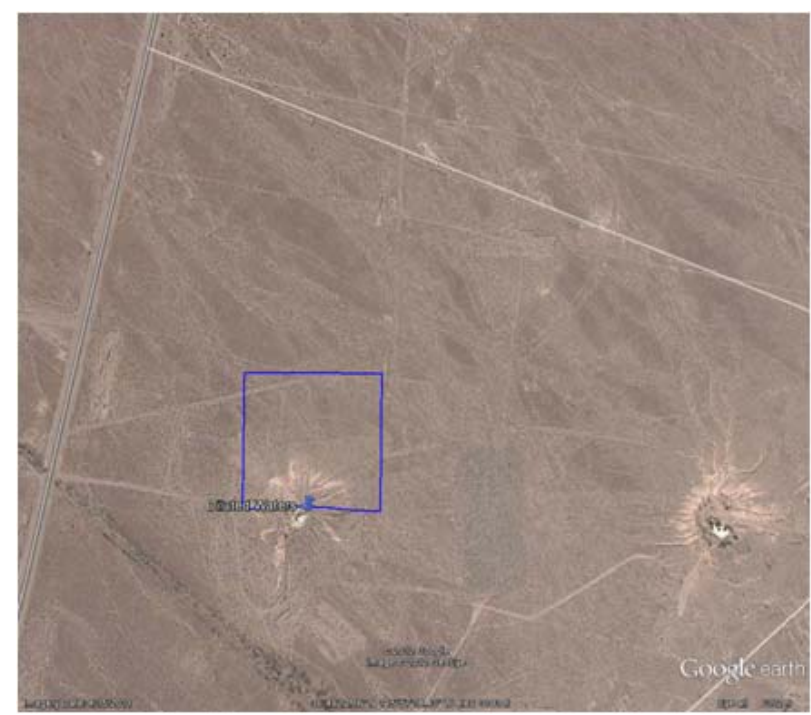

(a)

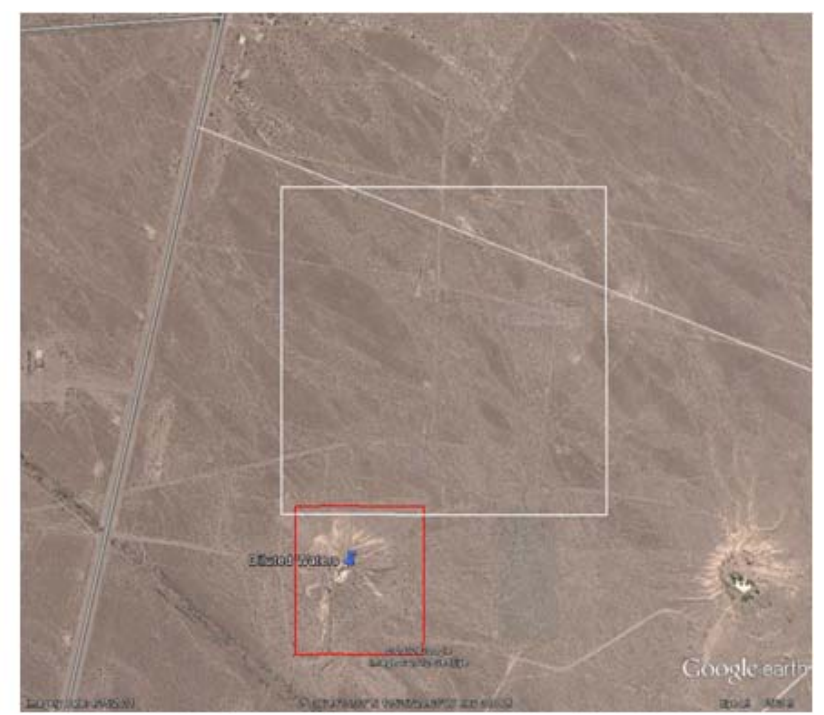

(b)

Figure 2: Google Earth aerial photos of the DILUTED WATERS site and surrounding area. (a) The area outlined in blue was the predetermined sampling area. (b) The areas outlined in white and red were the survey areas. Each area has its own distinct survey plan. Up is due north.

Table 1: Corner Coordinates for the Three Survey and Sampling Areas

\begin{tabular}{|c|c|c|c|c|c|c|}
\hline \multirow[t]{2}{*}{ Corner } & \multicolumn{2}{|c|}{ Sampling Area (Blue) } & \multicolumn{2}{|c|}{ Survey Area (Red) } & \multicolumn{2}{|c|}{ Survey Area (White) } \\
\hline & Latitude & Longitude & Latitude & Longitude & Latitude & Longitude \\
\hline NW & $36^{\circ} 49^{\prime} 11.62^{\prime \prime} \mathrm{N}$ & $115^{\circ} 57^{\prime} 28.52^{\prime \prime} \mathrm{W}$ & $36^{\circ} 49^{\prime} 8.20^{\prime \prime} \mathrm{N}$ & $115^{\circ} 57^{\prime} 28.21^{\prime \prime} \mathrm{W}$ & $36^{\circ} 49^{\prime} 24.00^{\prime \prime} \mathrm{N}$ & $115^{\circ} 57^{\prime} 29.08^{\prime \prime} \mathrm{W}$ \\
\hline NE & $36^{\circ} 49^{\prime} 11.62^{\prime \prime} \mathrm{N}$ & $115^{\circ} 57^{\prime} 20.43^{\prime \prime} \mathrm{W}$ & $36^{\circ} 49^{\prime} 8.20^{\prime \prime} \mathrm{N}$ & $115^{\circ} 57^{\prime} 20.26^{\prime \prime} \mathrm{W}$ & $36^{\circ} 49^{\prime} 24.00^{\prime \prime} \mathrm{N}$ & $115^{\circ} 57^{\prime} 9.00^{\prime \prime} \mathrm{W}$ \\
\hline SE & $36^{\circ} 49^{\prime} 5.27^{\prime \prime} \mathrm{N}$ & $115^{\circ} 57^{\prime} 20.52^{\prime \prime} \mathrm{W}$ & $36^{\circ} 49^{\prime} 0.86^{\prime \prime} \mathrm{N}$ & $115^{\circ} 57^{\prime} 20.27^{\prime \prime} \mathrm{W}$ & $36^{\circ} 49^{\prime} 7.82^{\prime \prime} \mathrm{N}$ & $115^{\circ} 57^{\prime} 8.94^{\prime \prime W}$ \\
\hline SW & $36^{\circ} 49^{\prime} 5.27^{\prime \prime} \mathrm{N}$ & $115^{\circ} 57^{\prime} 28.62^{\prime \prime} \mathrm{W}$ & $36^{\circ} 49^{\prime} 0.86^{\prime \prime} \mathrm{N}$ & $115^{\circ} 57^{\prime} 28.25^{\prime \prime} \mathrm{W}$ & $36^{\circ} 49^{\prime} 7.82^{\prime \prime} \mathrm{N}$ & $115^{\circ} 57^{\prime} 29.04^{\prime \prime} \mathrm{W}$ \\
\hline
\end{tabular}

Lesson Learned \#1: Taking coordinates from Google Earth can result in some errors. In a couple of instances, the position indicated on the figure and that indicated by actual Global Positioning System (GPS) coordinates were off by several tens of meters. This resulted in a quick need for additional approvals, such as pre-activity safety and wildlife surveys, in order to be able to survey in the areas we intended. To mitigate this issue, provide sufficient description of the sampling area where necessary to ensure that the correct locations are marked and that any required pre-activities are performed in the proper areas. 


\subsection{Dates and Schedule of Activities at DILUTED WATERS}

The activities for the DILUTED WATERS site were scheduled for 27-29 March 2012. The table below shows the envisioned activities and basic schedule for DILUTED WATERS prior to the actual campaign. Three PNNL staff (Jim Baciak, Randy Kirkham, and Brian Milbrath) participated, with Jim Baciak serving as the Activity Lead who did most of the pre-activity work. Due to a meeting in North Las Vegas, Brian Milbrath did not participate until the afternoon of the second day. PNNL staff were supported full-time by one NNSS technician (Michael Floyd) and one NNSS Radiation Control Technician (RCT), and part-time by one NNSS scientist (Dudley Emer) who served as a coordinator.

Table 2: Basic schedule for DILUTED WATERS Sampling and Survey Activities

\begin{tabular}{|c|c|c|c|}
\hline Activity & Date & Time & Notes \\
\hline $\begin{array}{l}\text { Shipment of Equipment } \\
\text { and Supplies }\end{array}$ & 20 MAR & N/A & Equipment will be shipped to NNSS for storage \\
\hline Arrival of Activity Lead & 27 MAR & 0630 & $\begin{array}{c}\text { Activity Lead (J. Baciak) will arrive in Las Vegas, NV } \\
\text { on the evening of } 26 \text { MAR }\end{array}$ \\
\hline $\begin{array}{l}\text { Briefing and Discussions of } \\
\text { NNSS Staff (Day 0) }\end{array}$ & 27 MAR & 0730 & $\begin{array}{l}\text { J. Baciak and D. Emer will discuss activity and setup } \\
\text { for survey and sampling at DILUTED WATERS. If time } \\
\text { permits, will begin sampling and survey activities at } \\
\text { DILUTED WATERS. As necessary training for J. Baciak } \\
\text { will be administered. }\end{array}$ \\
\hline $\begin{array}{c}\text { RSI (Vehicle Survey) System } \\
\text { Test }\end{array}$ & 27 MAR & 1230 & Test and Calibration of RSI system in Mercury, NV \\
\hline $\begin{array}{l}\text { Equipment checkout and } \\
\text { loading of off-road vehicles }\end{array}$ & 27 MAR & 1700 & $\begin{array}{c}\text { Load equipment into vehicle(s) for sampling and } \\
\text { survey activities. Check working order for all other } \\
\text { equipment. }\end{array}$ \\
\hline $\begin{array}{l}\text { Briefing and Discussion of } \\
\text { Day } 1 \text { Activities }\end{array}$ & $28 \mathrm{MAR}$ & 0700 & \\
\hline $\begin{array}{l}\text { Staking of Boundaries for } \\
\text { Sampling and Survey } \\
\text { Activities }\end{array}$ & $28 \mathrm{MAR}$ & 0800 & $\begin{array}{l}\text { J. Baciak and NNSS staff member will stake } \\
\text { perimeters of sampling and survey sites }\end{array}$ \\
\hline $\begin{array}{l}\text { Arrival of Sampling and } \\
\text { Survey Team }\end{array}$ & $28 \mathrm{MAR}$ & 1300 & R. Kirkham and B. Milbrath arrive in Mercury, NV \\
\hline $\begin{array}{l}\text { Sampling and Survey of } \\
\text { DILUTED WATERS }\end{array}$ & $28 \mathrm{MAR}$ & 1300 & Will continue until 1630. \\
\hline
\end{tabular}




\begin{tabular}{|c|c|c|c|}
\hline Activity & Date & Time & Notes \\
\hline $\begin{array}{l}\text { Briefing and Discussion of } \\
\text { Day } 2 \text { Activities }\end{array}$ & 29 MAR & 0700 & \\
\hline $\begin{array}{l}\text { Sampling and Survey of } \\
\text { DILUTED WATERS }\end{array}$ & 29 MAR & 0745 & Will continue until finished (no later than 1500) \\
\hline $\begin{array}{l}\text { Debriefing and Lessons } \\
\text { Learned }\end{array}$ & 29 MAR & 1545 & $\begin{array}{l}\text { Discussions of the activity with all participants, in } \\
\text { Mercury, NV }\end{array}$ \\
\hline $\begin{array}{l}\text { Sampling and Survey Team } \\
\text { leave NNSS }\end{array}$ & 29 MAR & 1730 & PNNL staff return to Las Vegas for Flights on 30 MAR \\
\hline $\begin{array}{l}\text { Shipment of Samples to } \\
\text { PNNL }\end{array}$ & 30 MAR & N/A & Ship samples to PNNL as soon as reasonably possible \\
\hline
\end{tabular}

The schedule was mostly followed according to the planned schedule above; we were able to accomplish the activity within the allotted timeframe. Getting equipment shipped out of PNNL took a bit longer than expected, partly due to late receipt of NNSS approval for the DILUTED WATERS activity. Paperwork and approval for shipping of hazardous materials (laptop batteries and imbedded radiation sources in detection equipment) took a day longer than planned. Also, some ordered equipment did not show up in time, and a few small items needed to be purchased at Home Depot in Las Vegas, NV prior to travelling to Mercury. Notes for each day's activities are summarized below.

\section{$\underline{27 \text { March }}$}

The day started with J. Baciak and R. Kirkham driving up to Mercury from Las Vegas. Training and safety discussions started at approximately 0730, and were completed around 1000. All equipment arrived safely and testing and calibration of the equipment was completed by about 1200 . Thus, we were able to start setup for the sampling and survey activities at DILUTED WATERS. Due to the general slope of the crater, we had to enter the crater by foot (carrying all equipment by hand), increasing the time needed to mark all sampling locations. One team set up the RSI detector to record data while another team placed stakes for the vehicle survey. All of the sampling positions and approximately half of the stakes for survey area north of the crater were set in place by the time we had to stop work early (approximately 1530) due to high winds. We returned to Mercury, unloaded the vehicles and completed the day at approximately 1630 .

\section{March}

We checked the operation of the RSI detector in Mercury and loaded all of the equipment into the trucks. Unfortunately, we had to wait until approximately 0840 before leaving Mercury because our RCT had other meetings/responsibilities to deal with before he could join us. We arrived at the DILUTED WATERS site and immediately set to work (at approximately 0930). R. Kirkham went to finish staking the survey location north of the crater, while J. Baciak started sampling from the predetermined locations in and 
around the DILUTED WATERS subsidence crater. Four small (5-10 g) samples, one $2^{\prime \prime} \times 4^{\prime \prime}$ soil core, and one $3^{\prime \prime} \times 6^{\prime \prime}$ soil core were taken from each sample location. Sampling at the 18 locations was completed by approximately 1300 . The sampling team then helped to finish staking the survey area. During the staking process, it was determined that the measuring wheel was failing and incorrectly measuring the distance to place stakes. It should be noted that the measuring wheel used was not the originally ordered heavy-duty model, which had not arrived in time for the DILUTED WATERS activity. Thus, we had to purchase one at a Home Depot in Las Vegas. When the wheel's electronics had become dirty due to the fine soil/dust of the site, the ability to properly measure in $10-\mathrm{m}$ increments was compromised. To correct the issue, we re-measured the stakes to ensure the proper spacing. Of the 100 stakes placed in the survey area, the final 15 needed to be re-staked. Staking was completed at about 1515.

At approximately 1500, B. Milbrath arrived at the DiLUTED WATERS site. At this point, it was decided to proceed with the 50-m survey spacing run with the RSI detector. This activity was completed at approximately 1630, after which we signed out at NPTEC and returned to Mercury to unload the vehicles and place the equipment indoors. The day was completed at about 1730.

\section{$\underline{29 \mathrm{March}}$}

The day proceeded on schedule. We arrived at the site around 0830. The two main activities for this day were to complete a 30-m spacing run with the RSI detector, and to perform in-situ sampling with the Ludlum 711 hand-survey system. In addition, we performed sampling near a hot spot discovered in the survey area during the first survey run yesterday. The survey with 30-meter line spacing was completed at 1145 . In-situ sampling was completed by approximately 1200, and sampling at the new location was completed by 1300 . Unfortunately, we were not allowed to sample directly at the hot spot location due to the RCT's detection of alpha contamination and possible exposure rates in excess of our work authorization. In addition to spectra recorded by the RSI and Ludlum instruments, Dudley Emer said he would take an HPGe detector out and record some spectra at this hot spot the following week. We returned to Mercury, unpacked the vehicles, unpacked the equipment, and closed out the activity. We left Mercury to return to Las Vegas at approximately 1445.

Lessons Learned \#2: When shipping inspection equipment, additional time may be necessary, particularly when equipment containing batteries or radioactive sources is involved, as these are considered to be hazardous materials. For NNSS, two weeks rather than one week may be necessary.

Lessons Learned \#3: Plan sufficient time for setup, calibration, and daily planning discussions. In particular, any setup in the field will generally require more time than expected due to potential complications and plan adjustments. While some future activities will not require as much setup time as the DILUTED WATERS activities, one should expect a minimum of a day in order to setup for future activities. In addition, make sure to add time for field setup of equipment. Even though equipment may be calibrated and tested at the base of operations (Mercury in this case), time is still required to set up to load equipment into trucks and offroad vehicles. This generally took about 20-30 minutes for everything. Be sure to account for this time when planning activities. 


\subsection{Vehicle-based Survey at DILUTED WATERS}

Vehicle-based survey was performed using one $2^{\prime \prime} \times 4^{\prime \prime} \times 16^{\prime \prime}$ NaI log RS-700 system from Radiation Solutions, Inc. (RSI 2007). The system was placed in the bed of a Kawasaki Mule ATV, and power was supplied through a $12 \mathrm{~V}$ adapter plugged into a cigarette lighter. As shown in Figure 3, the detector was in the back of the ATV and connected to a laptop, allowing an operator to monitor the data and notice alarms instantly. The operator also monitored a GPS handheld unit. The driver tried to steer in a straight line (while avoiding large brush and other obstacles) based on the GPS unit and also stakes placed at the survey boundary.

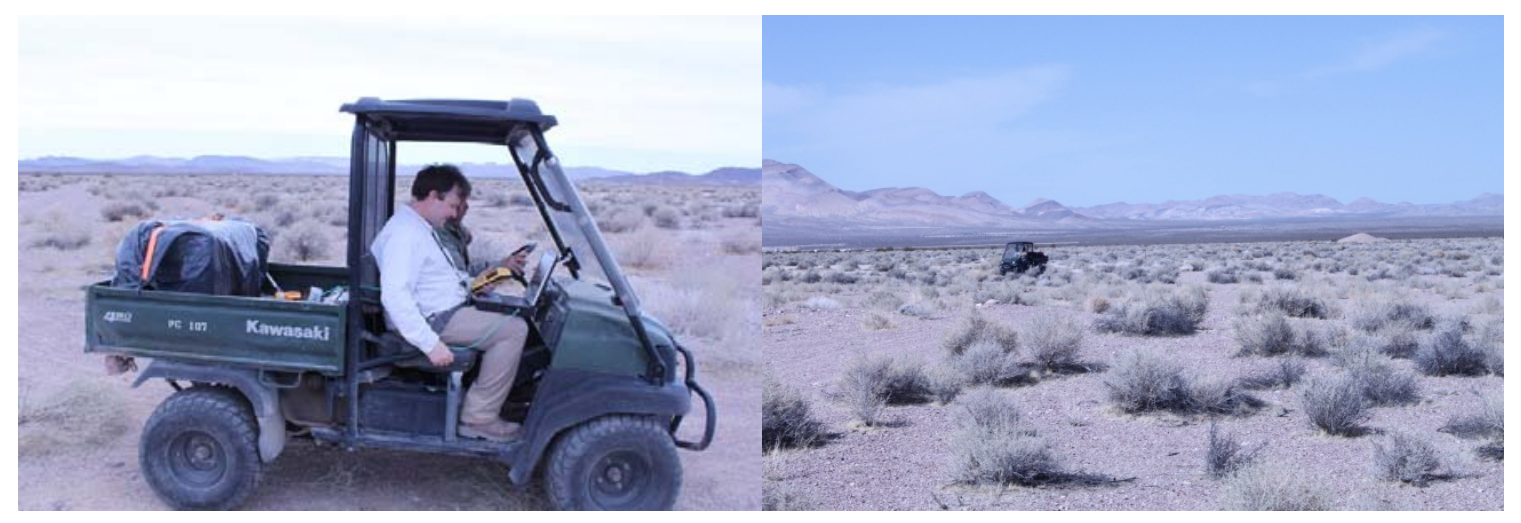

Figure 3: Conduct of vehicle surveys with RSI detector

For the survey around the subsidence crater, the vehicle drove around the rim of the crater at a nominal speed of 7-10 mph, and stayed mostly on the groomed path. Originally, we planned for the vehicle to enter the subsidence crater from the south end (where the slope is gradual) and drive in the crater itself. However, on closer inspection the ramp was too washed out to safely enter the crater. An additional (higher-accuracy) GPS recording device was used to corroborate position and test the GPS of the RSI system.

For the survey of the $500 \times 500 \mathrm{~m}^{2}$ area (depicted in white in Figure 2), the vehicle passed through the area using a general serpentine pattern with lines in the east-west direction. Two different spacings between lines were driven: $30 \mathrm{~m}$, and $50 \mathrm{~m}$. We originally intended to perform a10-m spacing, but it became clear during the 50- and 30-m spacing runs that it would be difficult to maintain a driving accuracy within the survey area to less than 10-15 m. Such tight spacing is likely not needed for a CTBT OSI, however, as a UNE vent would likely have a broader area distribution. Combined with time constraints, it was decided to cancel the 10 -m spacing run. All measurements were performed at a nominal velocity of approximately $3 \mathrm{mph}(5 \mathrm{~km} / \mathrm{hr})$. We originally planned to perform runs at different speeds (3, 5, and $10 \mathrm{mph}$ ). However, when performing the survey off-road, it was determined that only the $3 \mathrm{mph}$ (nominal) speed was safe for the RSI over the given terrain.

The GPS position recorded by the RSI system was compared with a higher-accuracy GPS system and an example of the results are shown in Figure 4, which displays the GPS marker for both the RSI and handheld GPS locators for the 50-m spacing run. As can be seen, the two GPS coordinates overlay one 
another for most of the measurement, with only a slight deviation in some locations. Even in these areas of deviation, the difference between the two units is less than $5 \mathrm{~m}$.

As Figure 4 shows, we also found a potential hotspot (the orange spot in the contour plotting). The location of increased radioactivity was not on any radiation maps of the site (primarily aerial) we saw prior to the measurement campaign, but was recognized instantly when we passed it while conducting the vehicle-based survey. Figure 5 shows the $50-\mathrm{m}$ spacing count rate. The location of the hotspot produced a gamma-ray count rate a factor of approximately 2.8 above background. This hotspot only showed up on one of the lines during the 50-m spacing run (seen in Figure 4), but appeared with varying intensity on three lines during the 30-m spacing measurement. This hotspot was located near the site of an old aircraft crash, which also caused us to have to deviate significantly from the originally planned path due to inaccessibility.

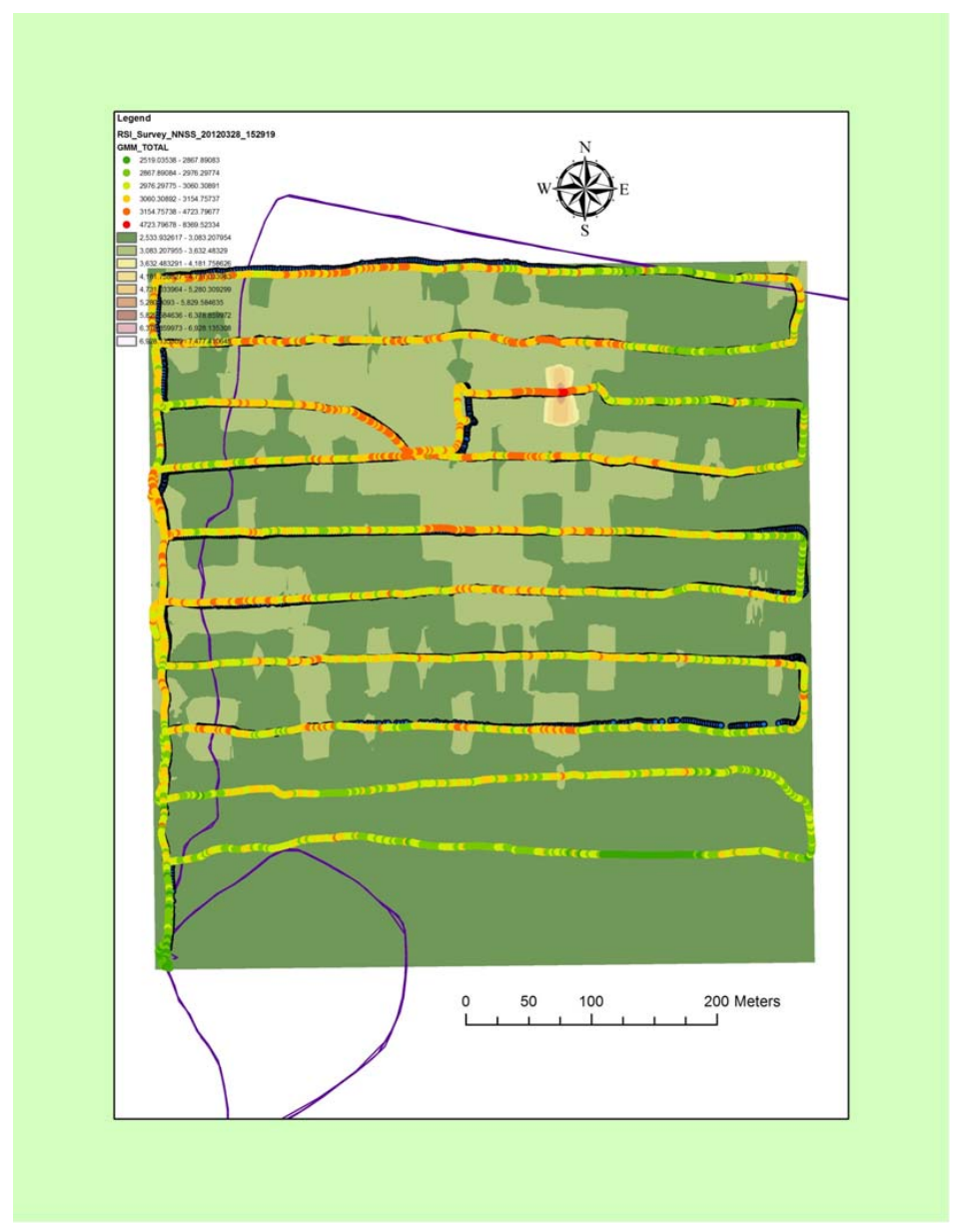

Figure 4: Overlay of the two GPS locators (one from the RSI system, one high-accuracy handheld). The multi-colored points are from the RSI system, and also show the count rate at that particular location. The darker points are from the high-accuracy handheld and closely match the RSI GPS. The purple line is not relevant to the discussion. 

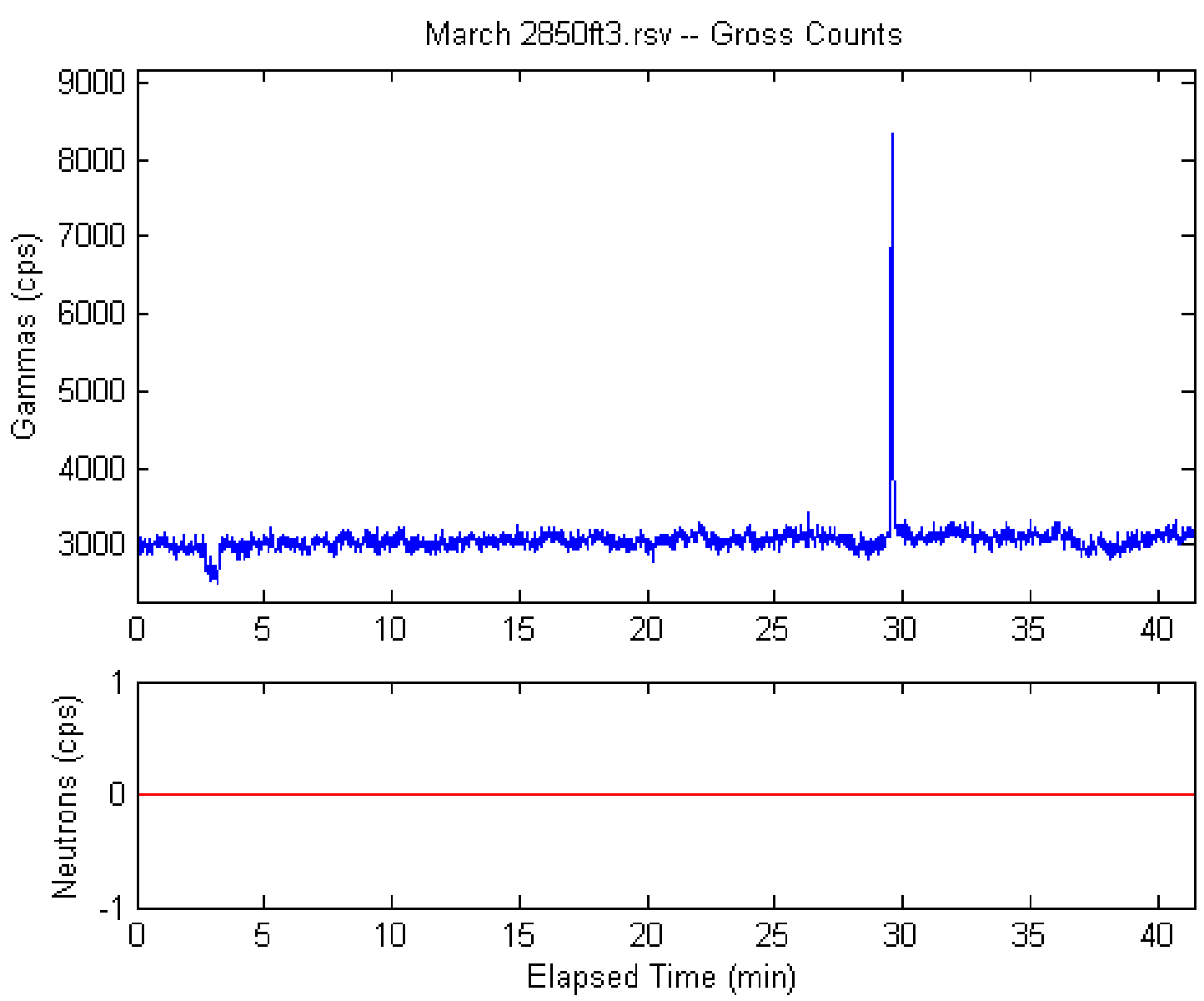

Figure 5: RSI system count rate during the 50-m spacing run. The spike was from a previously unidentified ground hotspot near the plane crash site near DILUTED WATERS.

During the 30-m spacing run we stopped the vehicle to record a long-dwell spectrum at the site of the high signature in order to ascertain what nuclides could be identified at this location. The results are shown in Figure 6, which is the background-subtracted radiation spectrum at this location. Although depleted uranium was seen in the area, the only identifiable peaks are associated with ${ }^{232} \mathrm{Th}$. This signature can be common near older military aircraft crash sites as aircraft have used thorium and thorium alloys for aircraft components. The use of the RSI system was deemed a success as we were able to identify a site of contamination that was not on previous aerial survey maps, although it was not from the actual DILUTED WATERS event itself. 


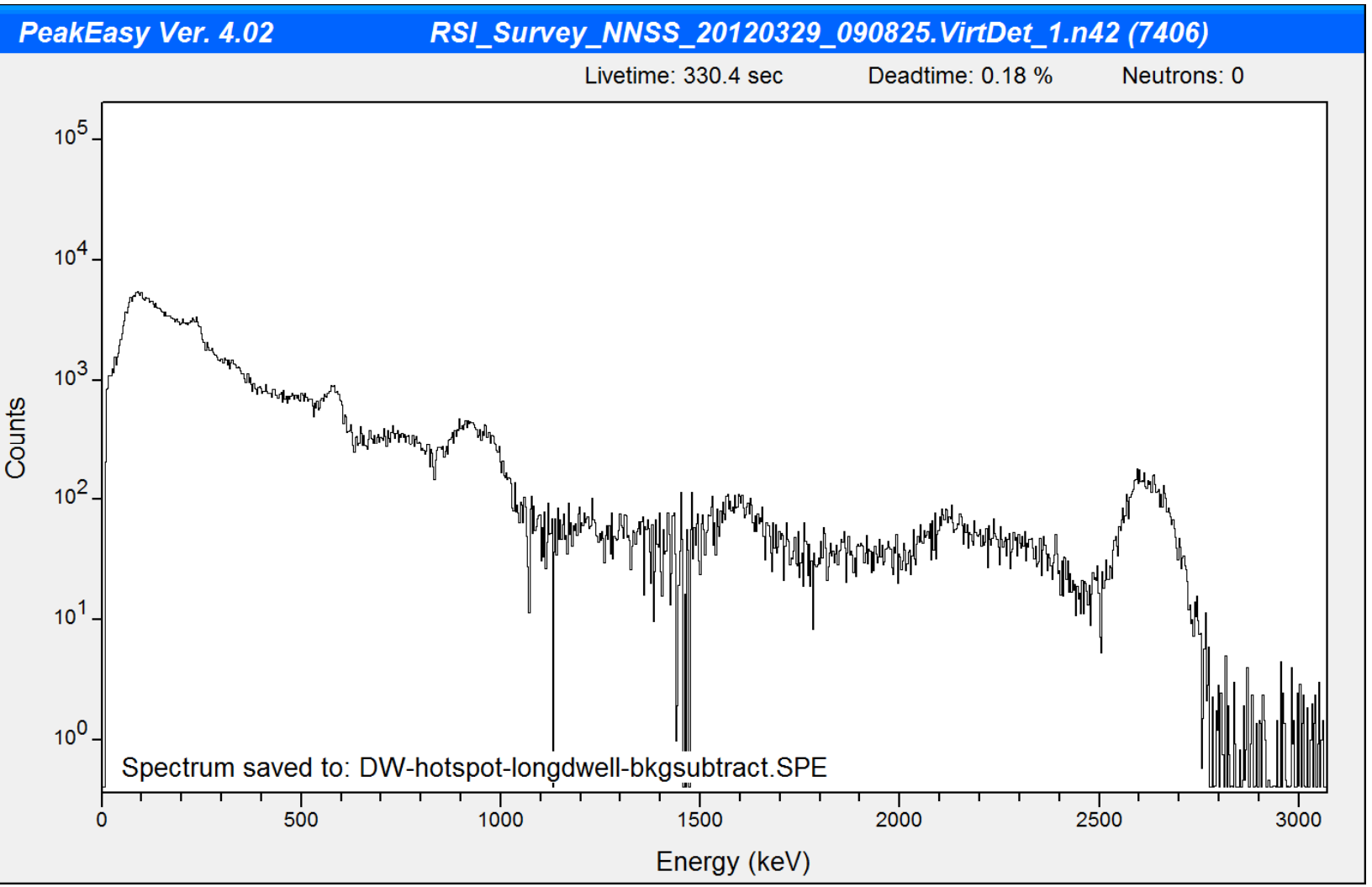

Figure 6: Background-subtracted long-dwell ( 5.5 minutes) spectrum from the RSI detector at the site of the hotspot in the DILUTED WATERS survey area. The peaks in the spectrum are associated with the decay of ${ }^{232} \mathrm{Th}$.

To further analyze the data, we applied an anomaly detection algorithm NSCRAD (Detwiler et al. 2010) to the data to develop better detailed statistical mapping of the contamination in the DILUTED WATERS survey area. As can be seen in Figures 7 and 8, the hotspot is clearly identifiable. The color-coded scale in both figures represents the standard deviation from background (sigma) for the anomaly detection algorithm's anomaly metric, with longitude and latitude represented by the $\mathrm{x}$ and y axes, respectively. The location of the hotspot appears as an elongated oval due to the 50-m spacing of the analyzed data. 


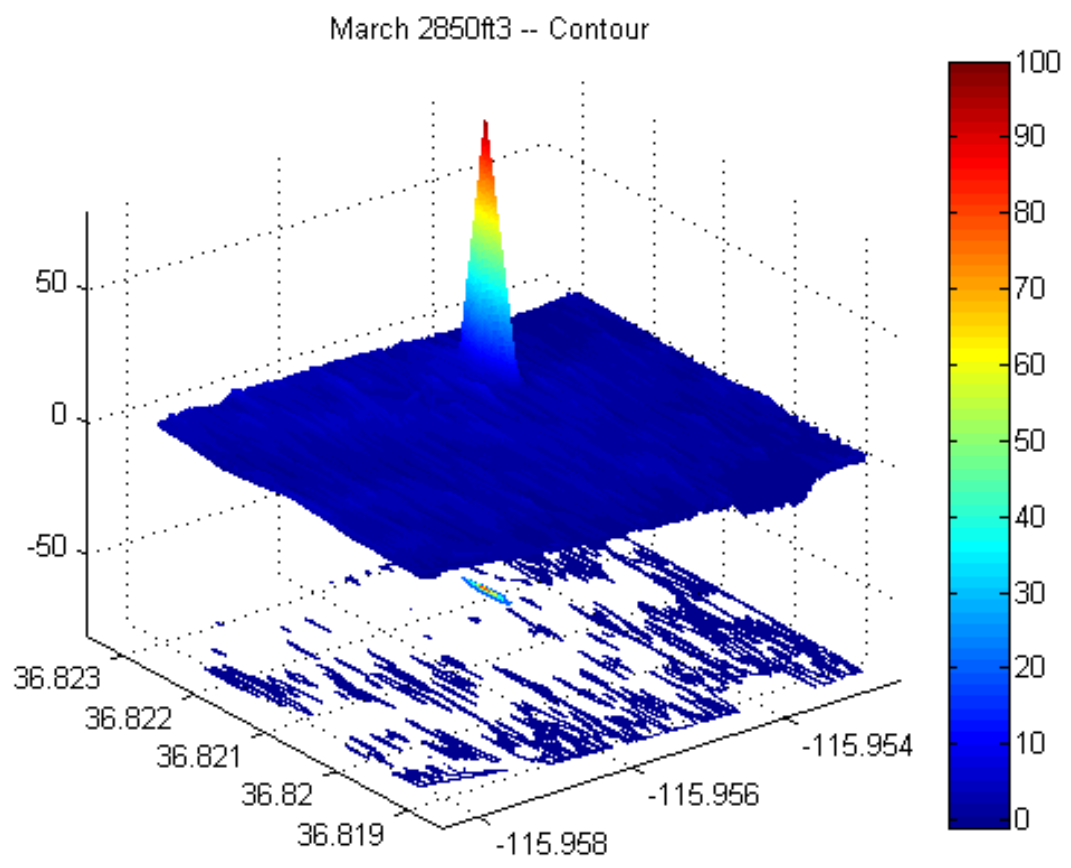

Figure 7: NSCRAD representation of the recorded radiation signature from the RSI detector. The data reconstructed in the figure is from the 50 -m spacing survey.

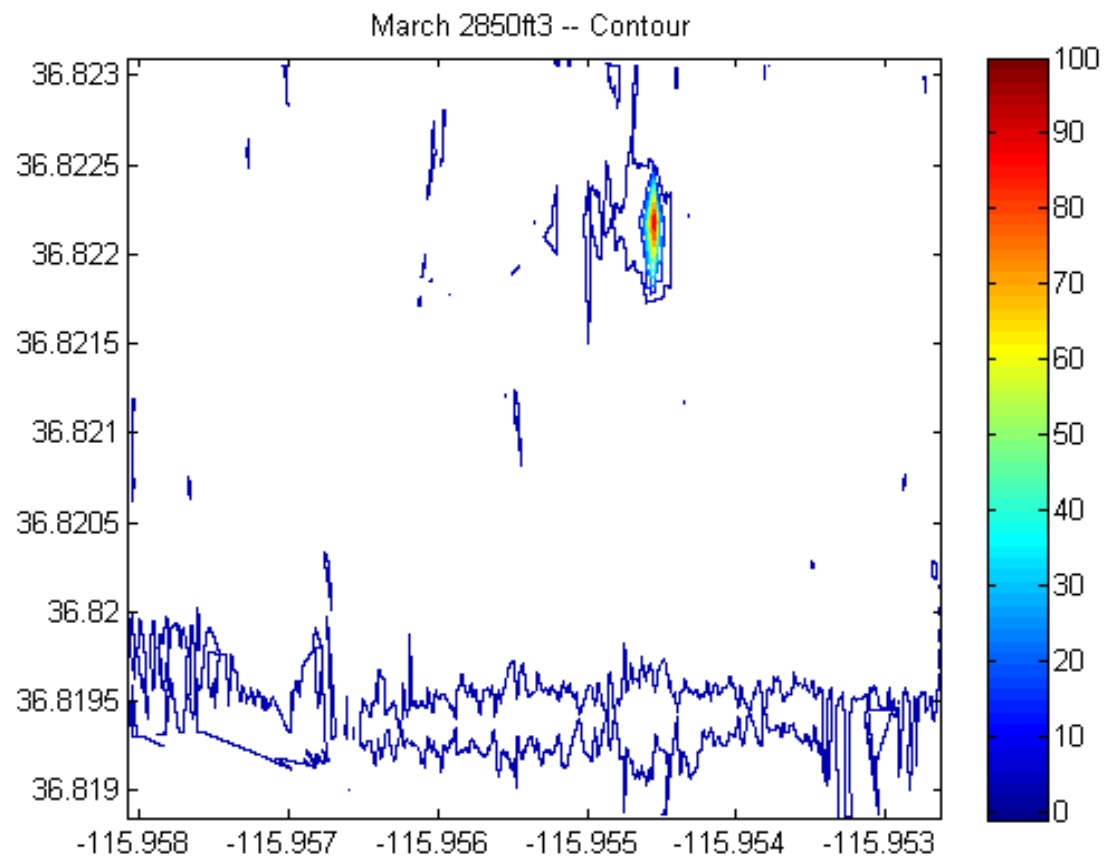

Figure 8: Two-dimensional representation of the NSCRAD results shown in Figure 7. An important feature to note is the noise located in the lower section of the graph. This was caused by poor selection of background and also due to some variation of count rate in the first serpentine line 
(seen as the depression in count rate in Figure 5). Improvements in NSCRAD settings and background selection should improve the results without disrupting the detection of the hotspot.

Lesson Learned \#4: When performing an off-road vehicle-based survey, the terrain will likely dictate maximum vehicle speed, which will generally be less than $5 \mathbf{m p h}$ $(\mathbf{8} \mathbf{~ k m} / \mathbf{h r})$. When planning for off-road vehicle survey, do not plan for anything higher than that and do not expect to be able to maintain a constant speed.

Lesson Learned \#5: Due to the rough conditions off-road in a desert-sagebrush landscape, performing a serpentine pattern with a spacing of $\mathbf{1 0} \mathbf{~ m}$ is impractical. The minimum possible distance between lines is $15-20 \mathrm{~m}$. It is unlikely that such a tight spacing as $10 \mathrm{~m}$ would be needed in a CTBT OSI anyway, as the source term from a UNE vent would be more broadly distributed.

Lesson Learned \#6: The operator of the survey detector system should concentrate only on the detector system itself, and not be expected to multitask by operating multiple pieces of equipment. The RSI detector system, for example, requires enough attention and multitasking itself to warrant the full attention of the operator. In particular, with rough terrain, power to the system can be easily lost and if one is not paying attention to the system, time/data will be lost.

Lesson Learned \#7: The GPS system associated with the RSI system is sufficiently accurate, to within at least the 30 -m serpentine pattern. In addition, comparison with a higher accuracy GPS system showed that the RSI GPS unit showed only minor differences in position.

Lesson Learned \#8: A GPS Lightbar would be preferable for conducting vehicle-based surveys to a handheld GPS unit. Our driver found keeping a straight line while looking at a handheld GPS unit with numerical output to be so difficult that instead we relied on staked flags to guide him. Putting up the stakes necessitated a lot of extra work that would frankly be better spent on other OSI activities. Also, it is not necessary for an OSI survey to have precisely-spaced coverage as it might be for, as an example, an environmental remediation survey or a survey looking for a pointsource. Vented UNEs are broader in extent, so that as long as a survey is adequately spaced it would not need the path precision of other types of radiation surveys.

\subsection{In situ Surveys at DiLUTED WATERS}

Limited in situ surveying was performed by the team. During the exercise, only a Ludlum $711 \mathrm{LaBr}_{3}$ handheld detector (Ludlum 2013) was available. Calibration and operation of the Ludlum 711 was very easy and it was relatively straightforward to figure out how to use the detector with minimal instruction. The batteries lasted the entire survey time each day (although the maximum number of hours of operation was not tested). 
The primary purpose of using the handheld Ludlum detector was to test its operation in the field and to investigate the unidentified hot spot picked up on the RSI detector during the first experimental run on March 28 (but some 5-minute measurements were also taken elsewhere). While the detector was relatively easy to use in the field, the screen was difficult to see in sunlight. Extracting the data from the detector, while straightforward, requires special software to download the data from the memory card.

Subsequent to our measurements, NCNS personnel took a Canberra 50\%-er Broad Energy HPGe detector (Canberra 2013b) to a few locations and set the detector up $1 \mathrm{~m}$ above the ground for measurements of 1-hour duration.

Example spectra for the two detectors are shown and discussed in the Laboratory Sample Analysis section.

Lesson Learned \#9: The screen brightness on handheld detectors may make them difficult to see in the field due to sunshine. It was often difficult to see the Ludlum 711's screen in the sunshine, preventing the observing of spectra in the field. Viewing was relatively easy during evening hours or under significant cloud-cover. Our experience is that this problem is not unique to this model of handheld, and this is not really something that can be tested "in the lab." Any handheld to be used in the field should be adequately tested in bright sunshine and a workable solution engineered.

\subsection{Environmental Sampling at DILUTED WATERS}

The sampling activity consisted of taking soil samples at various locations in the marked area shown in Figure 2(a). There were 18 prescribed sampling locations as shown in Figure 9. Table 3 shows the coordinates of the prescribed sampling locations. An additional sampling location was identified during vehicle survey: No. 19, which was near the location of the hotspot. The original intent was to actually sample in the hot spot, but the NNSS RCT did not grant permission due to the dose rate exceeding our scope of work. In addition, the RCT detected significant alpha activity, raising the concern of significant radiation exposure (including inhalation) if we were to disturb the soil. Thus, we could only sample near the site of the contamination. (During an actual OSI, presumably these issues would need to be overcome- unlike a survey, a sample cannot reveal what is nearby.) The coordinates for this location are included in Table 3. 


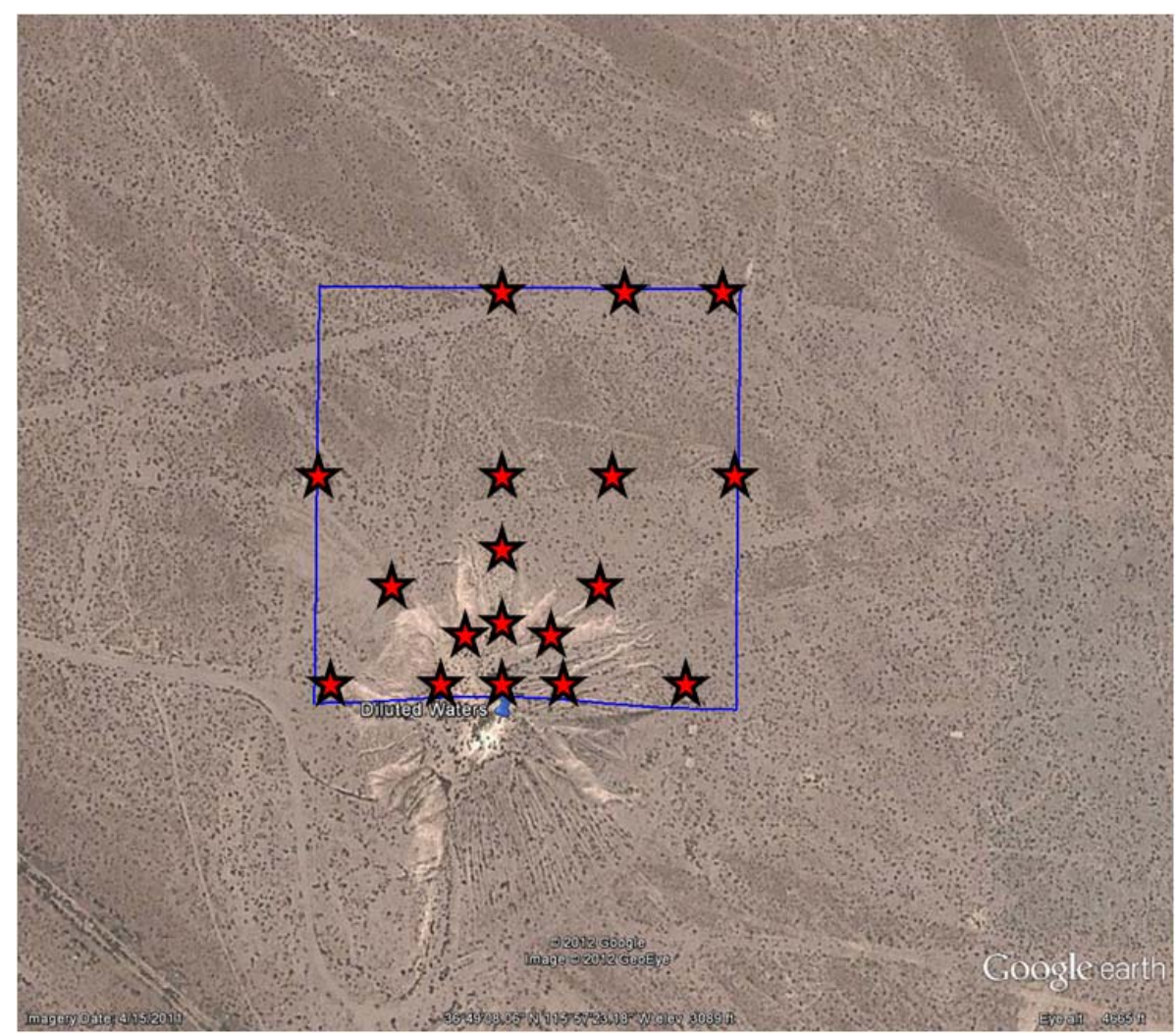

Figure 9: Sampling area for DILUTED WATERS showing sampling locations

Table 3: Fixed Sample Locations for DILUTED WATERS

\begin{tabular}{|c|c|c|}
\hline Sample Point & Latitude & Longitude \\
\hline 1 & $36^{\circ} 49^{\prime} 5.36^{\prime \prime} \mathrm{N}$ & $115^{\circ} 57^{\prime} 28.36^{\prime \prime} \mathrm{W}$ \\
\hline 2 & $36^{\circ} 49^{\prime} 5.22^{\prime \prime} \mathrm{N}$ & $115^{\circ} 57^{\prime} 26.53^{\prime \prime} \mathrm{W}$ \\
\hline 3 & $36^{\circ} 49^{\prime} 5.17^{\prime \prime} \mathrm{N}$ & $115^{\circ} 57^{\prime} 25.44^{\prime \prime} \mathrm{W}$ \\
\hline 4 & $36^{\circ} 49^{\prime} 5.19^{\prime \prime} \mathrm{N}$ & $115^{\circ} 57^{\prime} 24.53^{\prime \prime} \mathrm{W}$ \\
\hline 5 & $36^{\circ} 49^{\prime} 5.30^{\prime \prime} \mathrm{N}$ & $115^{\circ} 57^{\prime} 21.94^{\prime \prime} \mathrm{W}$ \\
\hline 6 & $36^{\circ} 49^{\prime} 5.93^{\prime \prime} \mathrm{N}$ & $115^{\circ} 57^{\prime} 26.10^{\prime \prime} \mathrm{W}$ \\
\hline 7 & $36^{\circ} 49^{\prime} 6.14^{\prime \prime} \mathrm{N}$ & $115^{\circ} 57^{\prime} 25.32$ "W \\
\hline 8 & $36^{\circ} 49^{\prime} 5.89^{\prime \prime} \mathrm{N}$ & $115^{\circ} 57^{\prime} 24.61^{\prime \prime} \mathrm{W}$ \\
\hline 9 & $36^{\circ} 49^{\prime} 6.91^{\prime \prime} \mathrm{N}$ & $115^{\circ} 57^{\prime} 27.01^{\prime \prime} \mathrm{W}$ \\
\hline
\end{tabular}




\begin{tabular}{|c|c|c|}
\hline Sample Point & Latitude & Longitude \\
\hline 10 & $36^{\circ} 49^{\prime} 7.92^{\prime \prime} \mathrm{N}$ & $115^{\circ} 57^{\prime} 25.36^{\prime \prime} \mathrm{W}$ \\
\hline 11 & $36^{\circ} 49^{\prime} 6.91^{\prime \prime} \mathrm{N}$ & $115^{\circ} 57^{\prime} 23.65^{\prime \prime W}$ \\
\hline 12 & $36^{\circ} 49^{\prime} 8.88^{\prime \prime} \mathrm{N}$ & $115^{\circ} 57^{\prime} 28.43^{\prime \prime} \mathrm{W}$ \\
\hline 13 & $36^{\circ} 49^{\prime} 8.88^{\prime \prime} \mathrm{N}$ & $115^{\circ} 57^{\prime} 25.39^{\prime \prime} \mathrm{W}$ \\
\hline 14 & $36^{\circ} 49^{\prime} 8.88^{\prime \prime} \mathrm{N}$ & $115^{\circ} 57^{\prime} 23.16^{\prime \prime} \mathrm{W}$ \\
\hline 15 & $36^{\circ} 49^{\prime} 8.88^{\prime \prime} \mathrm{N}$ & $115^{\circ} 57^{\prime} 20.78^{\prime \prime W}$ \\
\hline 16 & $36^{\circ} 49^{\prime} 11.51^{\prime \prime} \mathrm{N}$ & $115^{\circ} 57^{\prime} 25.30^{\prime \prime} \mathrm{W}$ \\
\hline 17 & $36^{\circ} 49^{\prime} 11.51^{\prime \prime} \mathrm{N}$ & $115^{\circ} 57^{\prime} 23.10^{\prime \prime} \mathrm{W}$ \\
\hline 18 & $36^{\circ} 49^{\prime} 11.51^{\prime \prime} \mathrm{N}$ & $115^{\circ} 57^{\prime} 20.66^{\prime \prime W}$ \\
\hline 19 & $36^{\circ} 49^{\prime} 18.7^{\prime \prime} \mathrm{N}$ & $115^{\circ} 57^{\prime} 18.3^{\prime \prime} \mathrm{W}$ \\
\hline
\end{tabular}

Our core sampling equipment (shown in Figure 10) was bought from AMS (AMS 2009) while plastic sample bags were purchased from ULINE (ULINE No year). At each site, we had intended to take six soil samples: Four with the Lock ' $\mathrm{n}$ Load soil sampling system, one with a 2 " $\times 4$ " core sampler ( 150-g samples), and one with a $3^{\prime \prime} \times 6^{\prime \prime}$ core sampler ( 600-g samples). Unfortunately, the fine sand of the DILUTED WATERS Area caused the plastic liners to get stuck in the core samplers as soil would become lodged between the metal sampler and plastic liner. As a result, we instead used garden trowels to take the "core" soil samples. Going into the exercise, our procedure for taking soil samples was as follows:

1. Go to the location prescribed in the log sheets. Should the immediate area be obscured by vegetation, rocks, or not be applicable for sampling, move a few meters in any direction such that sampling can be performed. Record the GPS location and stake the position with blue survey tape.

2. Using a $1 \mathrm{ft}$ square template, take samples with the Lock ' $\mathrm{n}$ Load tool at each corner. Samples should be taken inside the template approximately $2^{\prime \prime}$ from the edges. Tape both ends of the sample syringe. Place all four samples in a plastic bag. Record the sample ID and GPS location in the sampling log. Samples should be labeled such that the specific corner of the square template (NW, NE, SE, or SW) is known.

3. Using the 3 " soil sampler, insert the plastic liner in the core sampler. Take an approximate 6 " soil sample from the surface of the ground (near the center of the template). Remove the soil-filled plastic liner and cap each end. Tape both ends of the plastic liner and label it with a sample ID. Place sample in plastic bag and label bag. Record the sample ID and GPS location in the sampling log.

4. Using the $2^{\prime \prime}$ soil sampler, insert the plastic liner in the core sampler. Take an approximately 4 " soil sample from the surface of the ground (near the center of the template). Remove the soil-filled plastic 
liner and cap each end. Tape both ends of the plastic liner and label it with a sample ID. Place sample in plastic bag and label bag. Record the sample ID and GPS location in the sampling log.

5. Should the ground be too rocky/hard for easy sampling, use the auger tool to break-up the surface of the soil and acquire the sample(s). Note that use of the auger will cause the soil surface will become mixed with deeper soil.

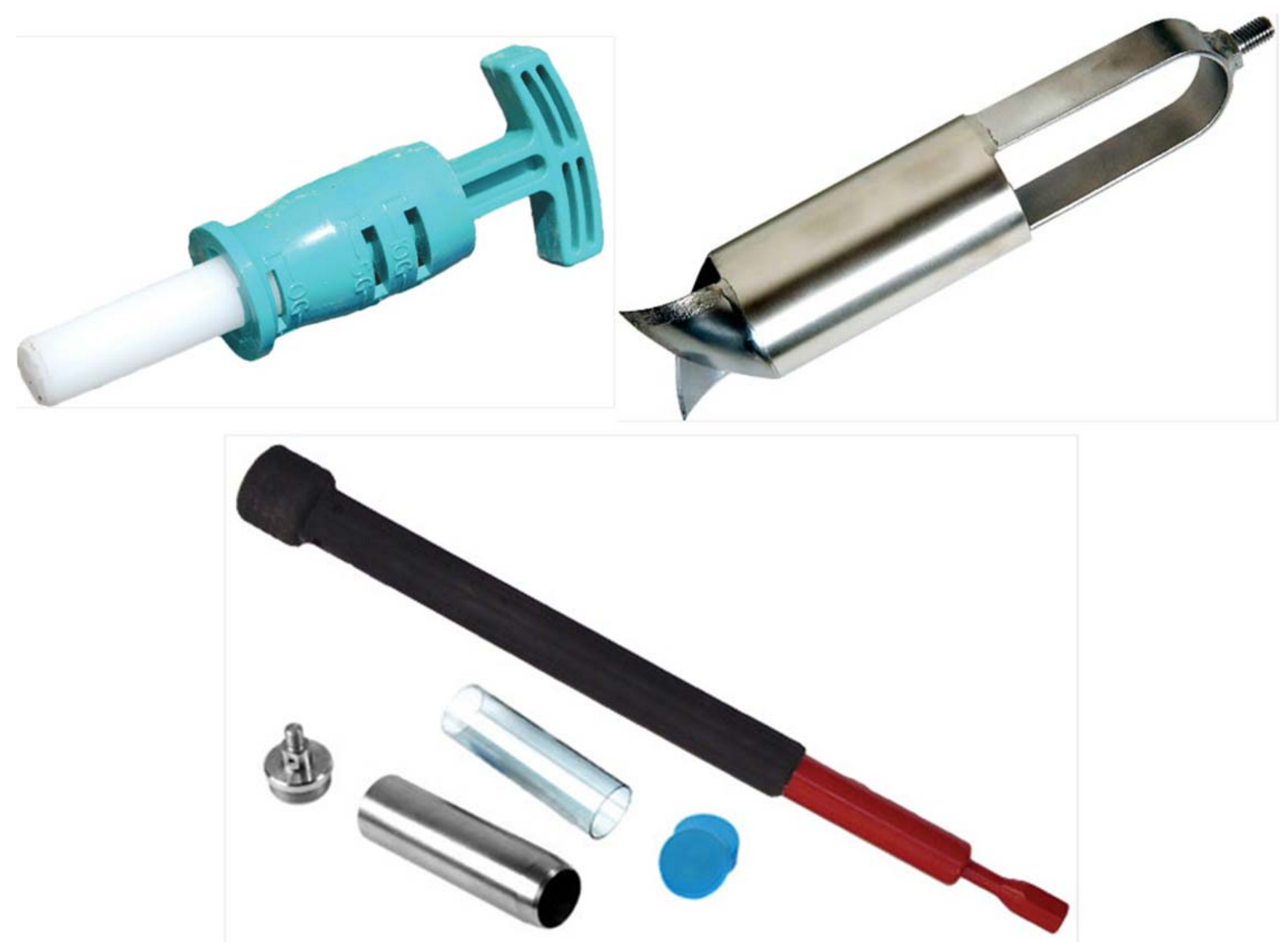

Figure 10: Soil sampling equipment used. Top Left: Lock N' Load soil sampling system. Top Right: Auger tool for breaking up surface if needed. Bottom: Core sampler. The plastic liner is inserted into the metal cylinder and then attached to the long handle. The plastic liner is capped and taped when removed.

The Lock 'n Load Soil sample syringes were developed to support U.S. Environmental Protection Agency-standard soil sampling techniques. We used them to extract 5-10 g of soil. In the end, these were not as effective as hoped due to our need to collect larger amounts of material for radiation measurements. While these may be useful for collecting samples in higher contamination soil, for the purpose of an OSI, in which one may be looking for radioisotopes at low levels amid the natural background and as quickly as possible, it makes more sense to take larger soil samples. This is also true for our case, in which we were trying to find low-level remnants of an old test release. 
Lesson Learned \#10: In general, the Lock ' $n$ Load system is not the right tool for collecting samples during an OSI. The total amount of soil (from a single vial) may not be sufficient for such measurements, unless there is a large concentration of radioactive material within the sample (from near a large release). There are more effective means of collecting soil samples.

Lesson Learned \#11: Split-core samplers may be more effective in gathering soil samples than general core samplers. Due to the very fine nature of NNSS soil around DILUTED WATERS, soil particles got trapped between the plastic liner and metal sampler. As a result, the plastic liner containing the soil sample got stuck and we had to use a hand shovel to collect soil. A hinged split core sampler would allow one to open the metal sampler and more easily remove the plastic liner.

Lesson Learned \#12: For a new release in which the material is at or very near to the surface, the usefulness of a core sampler is limited. However, one may want to use a core sampler at a new release site to obtain some soil composition/background radiation information. For old sites, assuming the issues in the previous Lesson Learned are addressed, core samplers can be an effective tool for collection soil.

Lesson Learned \#13: A more effective method for obtaining samples while preserving the depth sampled is needed. In particular, a device that allows one to take a soil sample with plates separating each centimeter of soil, and that does not require significant digging, would be very useful. PNNL has custom-built such systems in the past (Wogman et al. 2011).

Lesson Learned \#14: A simple method is needed to clean the sampling equipment after each collection to avoid potential cross-contamination. This is especially true for more expensive equipment such as core samplers or custom-built soil samplers.

Lesson Learned \#15: An OSI team should be prepared for the possibility of spot locations of contamination-level activity, possibly revealed only by alpha or beta measurement. An elevated level of activity may be discovered during an OSI that is inconsistent with the surroundings or expectations, requiring the ability to switch to Contamination Area procedures. In addition, such activity levels may be more noticeable via alpha and beta detection rather than gamma detection. It may be during an OSI that traditional alpha and beta radiation meters used for detecting radiation contamination will detect radiation that gamma survey and spectroscopic methods do not.

\subsection{Laboratory Sample Analysis}

The laboratory analysis of a select number of the soil samples taken from the DILUTED WATERS survey was conducted at PNNL. The laboratory sample analysis goals are listed below in order of importance:

- Investigation of the isotopic characterization of any hotspots seen in mobile and hand-held survey data

- Investigation of the presence of long-lived isotopes from past testing, such as ${ }^{137} \mathrm{Cs}$ 
- Investigation of possible location gradation of long-lived isotopes seen as evidence that the long-lived component resulted from DILUTED WATERS deposition

- Investigation of the presence of any long-lived isotopes in the crater produced by DILUTED WATERS

- Comparison of the sensitivity between techniques including vehicle survey, handheld detection and identification, HPGe in situ measurements, and laboratory sample analysis

- Comparison of the isotopic components of samples of different weights taken at one site

To address these questions, samples at select locations were analyzed. Table 4 shows which samples from the PRex survey of DILUTED WATERS were analyzed, including the actual weight of the sample. Also shown are the related measurement techniques for the sample available for comparison of methods.

Table 4: Summary of Samples Analyzed and Complementary Measurements

\begin{tabular}{|c|c|c|c|c|c|c|c|}
\hline Sample & $150 \mathrm{~g}$ sample & $\begin{array}{c}\text { Actual size } \\
\text { (g) }\end{array}$ & $600 \mathrm{~g}$ sample & $\begin{array}{c}\text { Actual size } \\
\text { (g) }\end{array}$ & $\begin{array}{l}\text { Mobile } \\
\text { Survey }\end{array}$ & $\begin{array}{l}\text { HPGe in } \\
\text { situ }\end{array}$ & $\begin{array}{l}\text { Hand- } \\
\text { Held }\end{array}$ \\
\hline 3 & $x$ & 210.8 & $x$ & 549.52 & & & \\
\hline 7 & & & $x$ & 583.4 & & & \\
\hline 10 & $x$ & 198.6 & $x$ & 621.9 & & $x$ & $x$ \\
\hline 13 & & & $x$ & 529.6 & & & \\
\hline 14 & $x$ & 265.0 & $x$ & 586.2 & & & \\
\hline 15 & & & $x$ & 580.1 & & & \\
\hline 17 & $x$ & 172.7 & $x$ & 549.1 & $x$ & & \\
\hline 19 & $x$ & 187.3 & $x$ & 643.5 & $x$ & $x$ & $x$ \\
\hline
\end{tabular}

Laboratory sample analysis was conducted using a calibration based on the average size of the relative sample size; for example, the approximately 150 -g and 600-g samples used different calibrations. HPGe spectra were taken over durations of 100,000 to 300,000 seconds, with an automated Canberra analysis routine, Apex-Gamma, based on Genie 2000 spectroscopy software (Canberra 2013a). Both the interference-corrected output of the automated routine and spectral analysis using PeakEasy software (Rooney 2006) were used in the evaluation of laboratory results. For ease of comparison, the results were summarized based on ratios of the quantity (activity per gram) of observed isotopes to sample 3 (center of crater). Ratios were calculated for each sample size (150 g or $600 \mathrm{~g}$ ) separately. The results are shown in the table below. PeakEasy ratios are based on ratios of count rates to sample 3 for the respective sample size. 
Table 5: Summary of Sample Laboratory Analysis Results

\begin{tabular}{|c|c|c|c|c|c|c|c|c|c|}
\hline Isotope & Sample 3 & Sample 3 & Sample 7 & Sample 10 & Sample 13 & Sample 14 & Sample 15 & Sample 17 & Sample 19 \\
\hline & $150 \mathrm{~g}(\mathrm{~Bq} / \mathrm{gm})$ & $600 \mathrm{~g}(\mathrm{~Bq} / \mathrm{gm})$ & $\begin{array}{l}600 \mathrm{~g} \\
\text { Ratio to } \\
\text { Sample } 3\end{array}$ & $\begin{array}{l}150 \mathrm{~g} / 600 \mathrm{~g} \\
\text { Ratio to } \\
\text { Sample } 3 \\
\end{array}$ & \begin{tabular}{|l}
$600 \mathrm{~g}$ \\
Ratio to \\
Sample 3 \\
\end{tabular} & $\begin{array}{l}150 \mathrm{~g} / 600 \mathrm{~g} \\
\text { Ratio to } \\
\text { Sample } 3 \\
\end{array}$ & \begin{tabular}{|l} 
600g \\
Ratio to \\
Sample 3 \\
\end{tabular} & \begin{tabular}{|l|}
$150 \mathrm{~g} / 600 \mathrm{~g}$ \\
Ratio to \\
Sample 3 \\
\end{tabular} & $\begin{array}{l}150 \mathrm{~g} / 600 \mathrm{~g} \\
\text { Ratio to } \\
\text { Sample } 3\end{array}$ \\
\hline$K-40$ & $\begin{array}{l}9.71 e-1+/- \\
3.5 e-2\end{array}$ & $\begin{array}{l}9.06 \mathrm{e}-1+/- \\
1.7 \mathrm{e}-2\end{array}$ & 1.11 & $1.0 / 1.01$ & 1.15 & $0.8 / 1.06$ & 1.15 & 0.99 & $1.1 / 1.16$ \\
\hline $\begin{array}{l}\text { Th-232 } \\
\text { daughters } \\
\text { (Canberra) }\end{array}$ & $\begin{array}{l}6.74 \mathrm{e}-2+/- \\
1.1 \mathrm{e}-3\end{array}$ & $\begin{array}{l}6.37 e-2+/- \\
6.0 e-4\end{array}$ & 1.23 & $1.11 / 1.22$ & 1.5 & $0.87 / 1.14$ & 1.27 & 1.17 & $2.81 / 2.85$ \\
\hline $\begin{array}{l}2614 \text { keV line } \\
\text { (PeakEasy) }\end{array}$ & & & 0.71 & $1.33 / 0.87$ & 1.14 & $0.77 / 1.15$ & 1.04 & 0.7 & $1.76 / 3.41$ \\
\hline $\begin{array}{l}\text { U-238 Nat } \\
\text { (Canberra) }\end{array}$ & \begin{tabular}{|l}
$3.95 e-2+/-$ \\
$6.0 e-4$
\end{tabular} & $\begin{array}{l}3.64 e-2+/- \\
3.1 e-4 \\
\end{array}$ & 1.1 & $1.09 / 1.18$ & 1.13 & $0.80 / 1.12$ & 1.19 & 1.1 & $1.08 / 1.17$ \\
\hline $\begin{array}{l}\text { U-238 Nat. } \\
\text { (PeakEasy), } \\
609 \text { keV and } \\
1765 \text { keV only }\end{array}$ & & & 0.64 & $1.51 / 1.24$ & 1.95 & $1.28 / 1.65$ & 1.54 & 1.14 & $1.08 / 1.32$ \\
\hline $\begin{array}{l}\text { Cs-137 } \\
\text { (Canberra) }\end{array}$ & $\begin{array}{l}1.67 e-3+/- \\
1.7 e-4\end{array}$ & $\begin{array}{l}1.9 e-3+/- \\
9.0 e-5\end{array}$ & 0.17 & $1.92 / 1.98$ & 10.1 & $1.92 / 3.52$ & 1.09 & 0.41 & $3.68 / 2.30$ \\
\hline $\begin{array}{l}\text { Cs-137 } \\
\text { (Peakeasy) }\end{array}$ & & & 0.07 & $1.78 / 1.18$ & 10.2 & 2.15/3.10 & 0.91 & 0.68 & $2.99 / 2.41$ \\
\hline
\end{tabular}

Local Hotspots: The first goal involved analysis of the soil samples taken at location 19; here mobile survey data showed a significant increase in the total count rate, and an NSCRAD anomaly metric on the order of 100 sigma above background. Therefore, a sample was analyzed as close to the location of the mobile hit as possible, but not at the exact location as explained in the previous section. Sample results for both sizes of samples revealed an excess of ${ }^{232} \mathrm{Th}$ by a factor close to three times that of the other samples analyzed. Other background components (natural ${ }^{238} \mathrm{U}$ and ${ }^{40} \mathrm{~K}$ ) were relatively constant among samples. The large sample taken at location 19 (600 g) also shows possible evidence of depleted uranium (DU) with a strong ${ }^{234 \mathrm{~m}} \mathrm{~Pa} 1001-\mathrm{keV}$ line approximately five times that seen in other samples with no increase in ${ }^{238} \mathrm{U}$ daughters, as shown in Figure 11. It should be noted, however, that the Genie2000 software did not recognize this as a detection of ${ }^{234 \mathrm{~m}} \mathrm{~Pa}$, since no other relevant gamma rays for that isotope were detected. Figures 12 and 13 show the corresponding $\mathrm{HPGe}$ and $\mathrm{LaBr}_{3}$ in situ spectrum (described in the previous section) taken at the sample location.

Long-Lived Isotopes: Another analysis goal was to see if long-lived radioisotopes from DILUTED WATERS could still be detected by gamma spectroscopy. Cesium-137 is the most prevalent fission radionuclide in old nuclear test debris and all samples showed ${ }^{137} \mathrm{Cs}$ present in different amounts. Cesium-137 is often seen worldwide in backgrounds from old atmospheric nuclear testing, however, and this would be especially true at NNSS. Unfortunately, other long-lived gamma-emitting fission products most likely to be nuclear test debris, such as ${ }^{125} \mathrm{Sb}$, would be at activity levels several orders of magnitude less than ${ }^{137}$ Cs. Though looked for, these were not seen. It may be that other analysis methods such as beta- or alpha-spectroscopy or mass spectroscopy would reveal more proof of the presence of other longlived fission products, but such techniques are not envisioned for a CTBT OSI. 
PNNL-22494

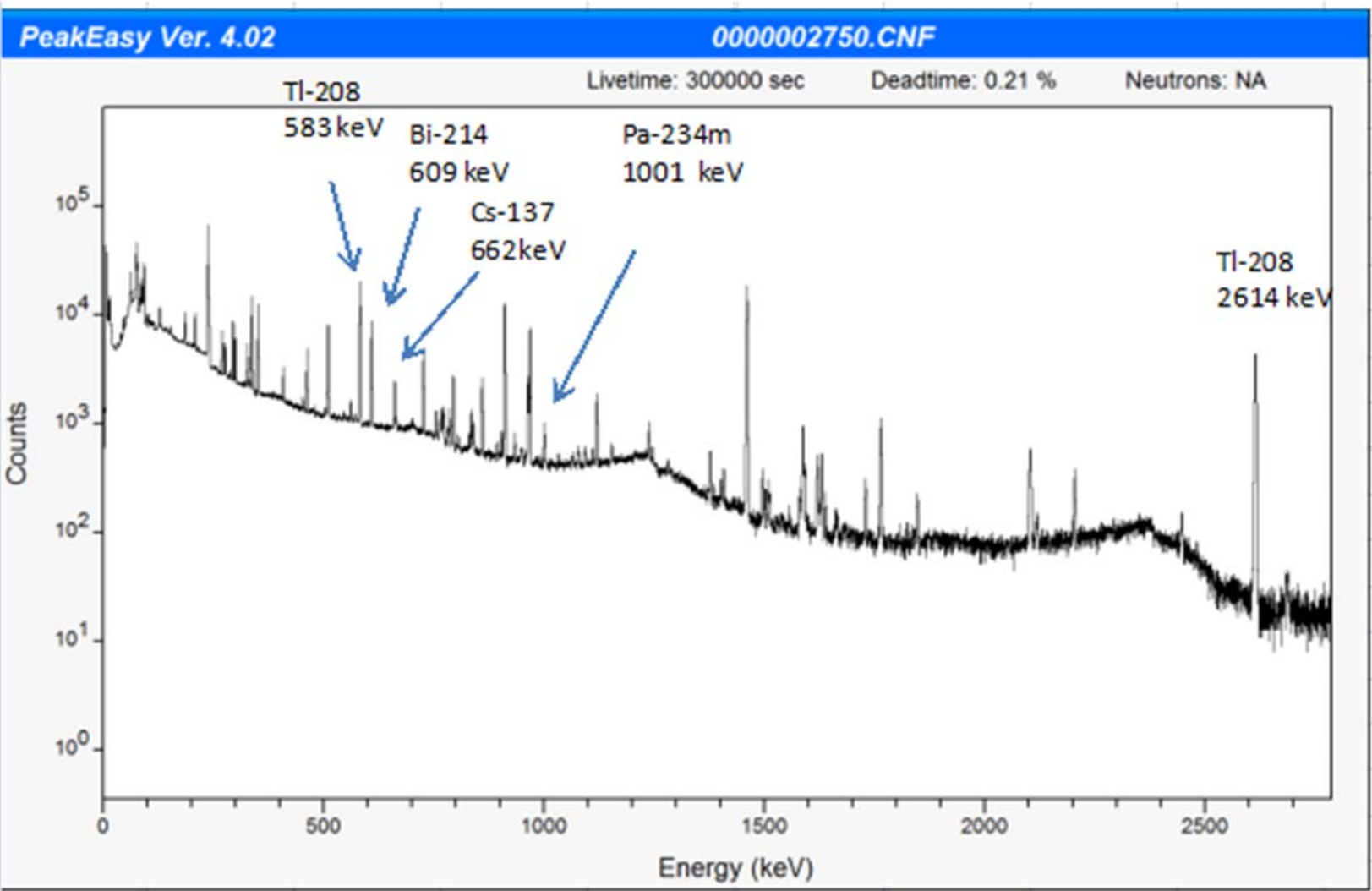

Figure 11: Laboratory analysis spectrum from sample 19 showing excess of ${ }^{232}$ Th daughters and indication of DU through the $1001-\mathrm{keV}^{234 \mathrm{~m}} \mathrm{~Pa}$ line 
PNNL-22494

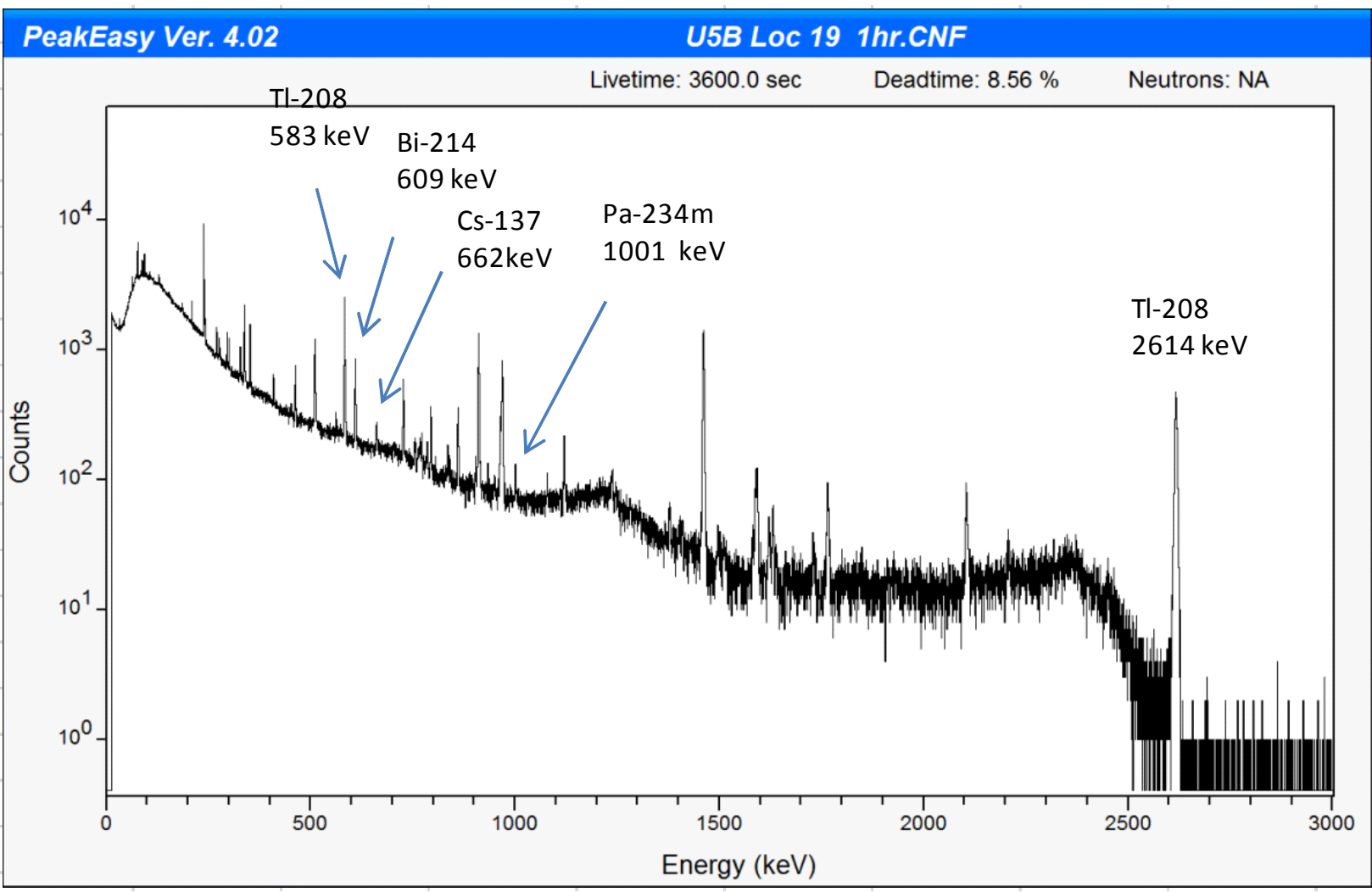

Figure 12: HPGe in situ spectrum from the location of sample 19 showing excess of ${ }^{232}$ Th daughters and indication of DU through the $1001-\mathrm{keV}^{234 \mathrm{~m}} \mathrm{~Pa}$ line 


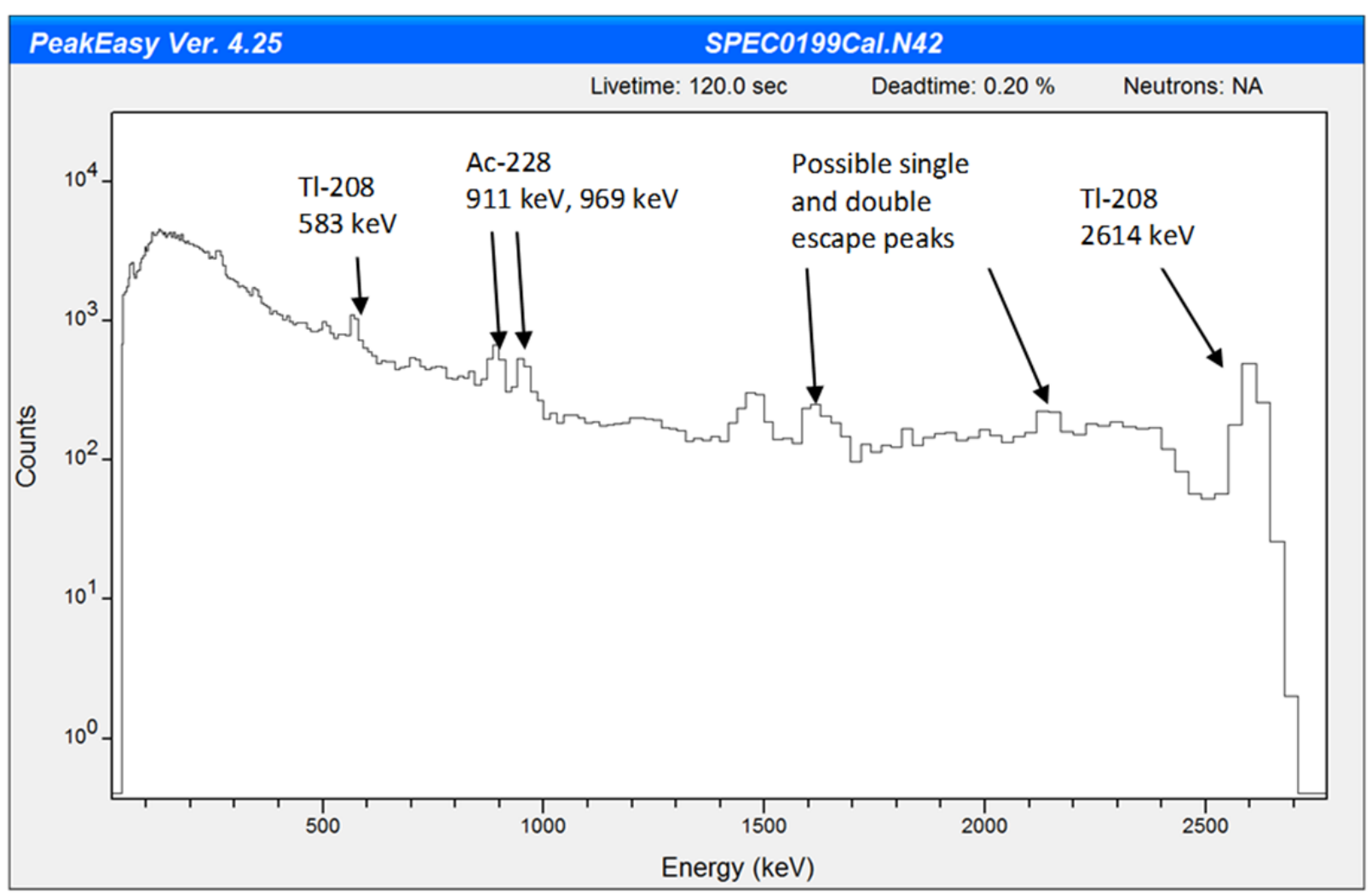

Figure 13: $\mathrm{LaBr}_{3}$ Hand-held spectrum form location 19 showing excess ${ }^{232}$ Th daughters

Gradation of ${ }^{137} \mathrm{Cs}$ : Since ${ }^{137} \mathrm{Cs}$ is likely ubiquitous in NNSS backgrounds, we looked at several samples to see whether a gradation in the measurements could be conclusively related to DILUTED WATERS. Recall that the vent plume traveled to the north of the event. Results from samples 3, 7, 10, 13, 14, 15 and 17 show possible, but probably not definitive, gradation of the ${ }^{137} \mathrm{Cs}$ content due to the event. The ${ }^{137}$ Cs content of the other samples is shown as a ratio to that of sample 3 in Figure 14. While at SGZ (the crater), it should be remembered that the collapse of the crater ended the venting, so one would not expect high levels of vent products at sample 3 or 7 unless deposited by a lingering plume. Sample 7 shows approximately 0.2 times the ${ }^{137} \mathrm{Cs}$ content of sample 3, sample 10 twice, sample 13 ten times, sample 14 two to four times, and sample 17 0.4-0.7 times the content of sample 3. It was felt that the sample locations immediately outside the crater, such as sample 10, showed evidence of possible surface modification after the event, due to actions such as clean-up crews driving around, whereas those locations further from the crater were more likely to be pristine. The results may suggest a northerly distribution of the plume products, but more samples, including some in non-plume areas, would be needed to establish this. It is worth noting that sample 19 (not shown on the map but north of the samples shown) also shows a two to four times increase in ${ }^{137}$ Cs content as compared to sample 3, which may indicate some variability of ${ }^{137} \mathrm{Cs}$. It is important to remember that at a recent-event OSI, the short-lived radioisotopes detected would not have world-wide backgrounds like ${ }^{137} \mathrm{Cs}$, and thus any plume would likely be easier to discern. 


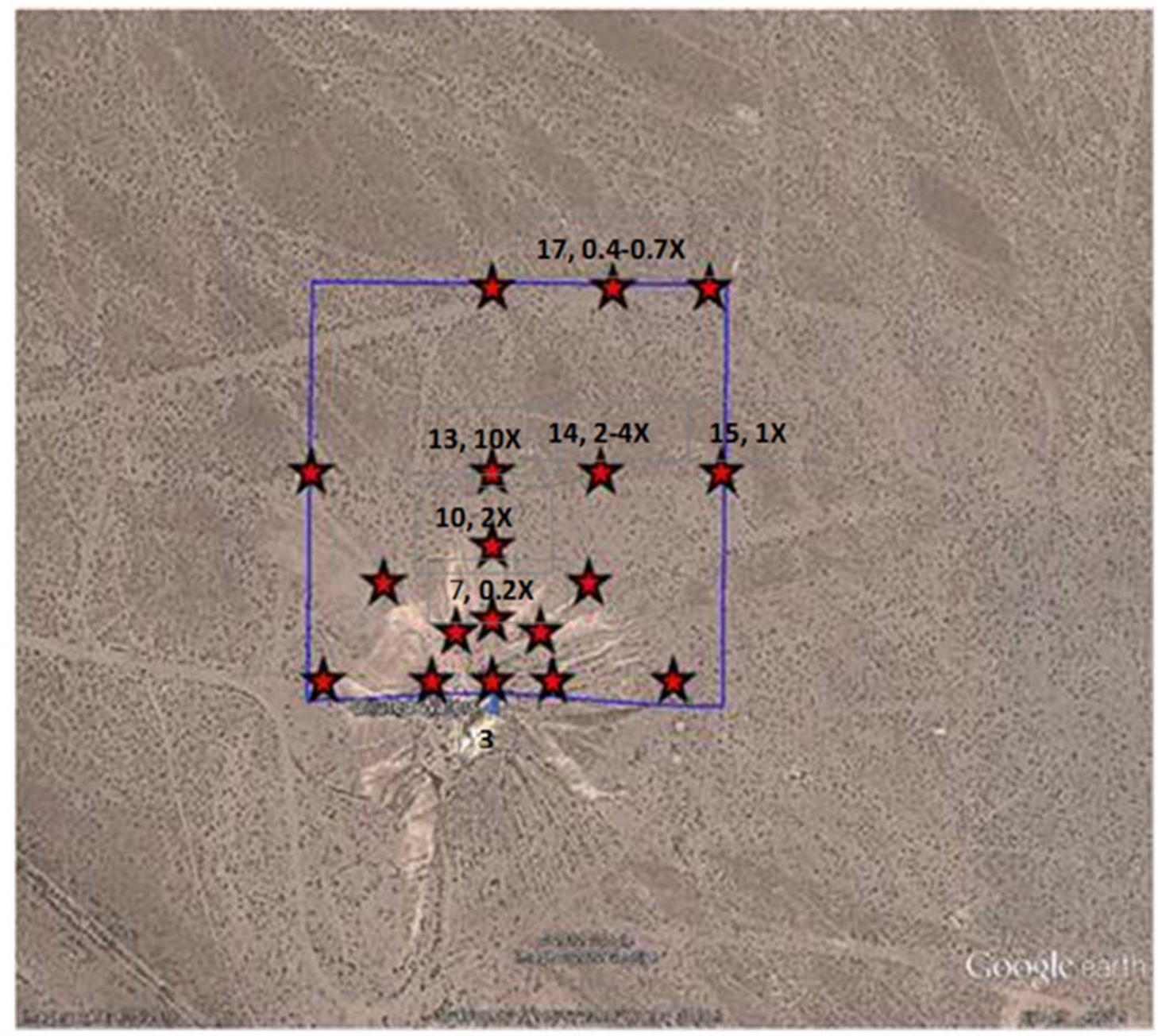

Figure 14: Sample Locations at DILUTED WATERS and relative ${ }^{137}$ Cs content (normalized to content of sample 3)

Comparison of Sensitivity of Survey Methods: In comparing methods, as noted in Table 4, overlapping HPGe in situ measurements were made for samples 10 and 19. Handheld measurements were made for sample 10 and mobile vehicle survey for samples 17 and 19 . Therefore, location 19 represents a comparison of mobile survey, laboratory analysis, HPGe in situ and hand-held methods. As mentioned above, the laboratory analysis of soil samples revealed an excess of ${ }^{232} \mathrm{Th}$ daughters by a factor of two to three times the content in other sample locations; this identification of excess ${ }^{232} \mathrm{Th}$ was consistent with spectral data from the mobile survey. The laboratory analysis also revealed an excess of the 1001-keV peak, indicating possible depleted uranium (DU) (Figure 11). Evidence of DU was not seen in the lower-resolution and shorter-dwell-time measurements of the mobile $2^{\prime \prime} \times 4^{\prime \prime} \times 16^{\prime \prime} \mathrm{NaI}$ or the hand-held $\mathrm{LaBr}_{3}$ detectors. However, both of these methods showed an excess of ${ }^{232} \mathrm{Th}$ daughters, which is a much stronger signal. The HPGe in situ measurements (Figure 12) compared well to the laboratory analysis, and showed the excess of ${ }^{232}$ Th daughters compared to other HPGe in situ measurements (locations 9-11, 19), as well as a possible indication of DU. 
Location 10 allows a comparison between HPGe in situ, $\mathrm{LaBr}_{3}$-based hand-held measurements, and laboratory analysis methods. In both locations 19 and 10, HPGe measurements showed an increase in the ${ }^{137}$ Cs content in keeping with the laboratory analysis results. In situ results shows an increase of two times for sample 10, and three times for sample 19, compared to the lowest value measured, with other background ratios close to constant in in-situ measurements. Laboratory results showed an increase of twice the ${ }^{137}$ Cs content in activity per gram for sample 10 and $2.3-3.7$ times for sample 19 , relative to sample 3. The $\mathrm{LaBr}_{3}$ handheld detector did not detect ${ }^{137} \mathrm{Cs}$.

Table 6 below shows a comparison of minimum detectable activity (MDA) values for ${ }^{137} \mathrm{Cs}$ and ${ }^{232} \mathrm{Th}$ for the spectral methods used. The MDA values for the laboratory analysis and in situ measurements are calculated through the software. The hand-held MDA value for ${ }^{137} \mathrm{Cs}$ is estimated based on the background of the peak area, distance from the source, counting time and assumed efficiency. For ${ }^{232} \mathrm{Th}$, the hand-held value is based on peak and background values of prominent daughter lines. For hand-held values, a conversion to Becquerels per gram is estimated from ratios of peak and background count rates to those of the in situ values. A determination of these values in terms of Becquerels per square meter would allow comparison with survey techniques as well and be of value to OSI development.

Table 6: MDA Comparisons between Screening Methods for ${ }^{137} \mathrm{Cs}$

\begin{tabular}{|c|c|c|c|c|c|}
\hline Method & $\begin{array}{c}\text { Cs-137 MDA } \\
(\mathrm{Bq} / \mathrm{g})\end{array}$ & $\begin{array}{l}\text { Measured Value } \\
\qquad(\mathrm{Bq} / \mathrm{g})\end{array}$ & $\begin{array}{c}\text { Th-232 MDA } \\
\text { (Bq/g) }\end{array}$ & $\begin{array}{l}\text { Measured } \\
\text { Value } \\
(\mathrm{Bq} / \mathrm{g})\end{array}$ & $\begin{array}{l}\text { Counting } \\
\text { time(s) }\end{array}$ \\
\hline $\begin{array}{l}\text { Laboratory } \\
\qquad 150 \mathrm{~g}\end{array}$ & $5.75 e-4$ & $\begin{array}{c}6.15 e-3+/-3.4 e- \\
4\end{array}$ & $5.12 \mathrm{e}-3$ & $\begin{array}{c}1.89 \mathrm{e}-1+/- \\
1.88 \mathrm{e}-2\end{array}$ & 200,000 \\
\hline $\begin{array}{l}\text { Laboratory } \\
600 \mathrm{~g}\end{array}$ & $2.92 \mathrm{e}-4$ & $\begin{array}{c}4.57 e-3+/-9.0 e- \\
5\end{array}$ & $2.55 e-3$ & $\begin{array}{c}1.81 \mathrm{e}-1+/- \\
8.26 \mathrm{e}-4\end{array}$ & 300,000 \\
\hline In situ HPGe & $2.41 \mathrm{e}-3$ & $\begin{array}{c}4.72 \mathrm{e}-3+/- \\
5.52 \mathrm{e}-4\end{array}$ & $9.96 \mathrm{e}-3$ & $\begin{array}{c}1.85 e-1+/- \\
4.43 e-3\end{array}$ & 3600 \\
\hline Hand-held LaBr & $1.3 e-2$ & Not measured & $4.40 \mathrm{e}-2$ & $1.17 e-1$ & 120 \\
\hline
\end{tabular}

Differences Between Samples: Overall, the NORM/background content was fairly constant between the small (nominal $150 \mathrm{~g}$ ) and large (nominal $600 \mathrm{~g}$ ) samples in laboratory analysis. The table below shows average values for the two sample sizes. NORM content for individual samples also showed close comparison, though not within measurement uncertainty, possibly reflecting natural difference within the sample. A similar excess of ${ }^{232}$ Th in sample 19 was seen in both sample sizes (Table 6 above). Larger differences were seen in the Cs-137 content as a function of sample size as seen in Table 5 and Table 6. Measured ${ }^{137}$ Cs content of the small and large samples varied by close to a factor of two for sample 14, and by roughly $30 \%$ for sample 19 . This may reflect larger differences within the soil samples for this man-made radioisotope. A more detailed study in which care was taken to sample at certain depths would 
be able to ascertain this. Likewise, an analysis of a 150-g versus a 600-g sample, where the 150-g sample is taken from a robustly mixed 600-g sample, might shed light on whether the small NORM differences measured between sample sizes were due to natural variation or experimental procedure.

Table 7: Average NORM content for Nominal Sample sizes

\begin{tabular}{|c|c|c|c|}
\hline $\begin{array}{c}\text { Nominal Sample } \\
\text { Size }(\mathrm{g})\end{array}$ & \multicolumn{3}{|c|}{ Average NORM Content (Bq/g) } \\
\hline & K-40 & Th-232 & U-238 \\
\hline 150 & 0.9594 & 0.09059 & 0.03884 \\
\hline 600 & 0.993 & 0.0874 & 0.0402 \\
\hline
\end{tabular}

Lesson Learned \#16: If samples containing short-lived isotopes are to be analyzed off-site, the procedures need to be worked out in advance. Transferring samples from NNSS to PNNL was slower than expected and would have been problematic had the samples involved short-lived isotopes. Samples were collected into shipping containers (usually small drums) that NNSS had to measure before releasing. PNNL required a measured spectrum of the soil so that it could be determined whether or not to treat the incoming material as radioactive or not. If so, additional paperwork would be needed. Internal shipping personnel were involved at both ends. Though the process could have been streamlined if knowledgeable staff had prioritized the effort, it would still have involved some delay. Delay can also happen due to weekend work closure on either end. It should also be noted that, though it was not the case for this effort, sometimes the shipment of soil itself can be problematic and subject to quarantines.

Lesson Learned \#17: It is important when collecting samples to try to locate areas that are pristine and do not appear to have been modified after the event. This was very difficult to determine at a 50-year-old site but may be easier at a newer site. It may be best not to take samples as close as possible to a site, if there are indications that people or vehicles have disturbed the soil, but rather locate a spot nearby where there is no such disturbance.

Lesson Learned \#18: The best place to sample a crater is likely not in the crater itself. Usually a crater is formed during the process that ends the vent, or sometime afterward. Thus the soil at the top of a crater may in fact be new-surface soil first exposed during the collapse rather than soil contaminated by a vent.

Lesson Learned \#19: Background samples are a necessary part of an OSI. They provide a basis for determining whether something seen in a sample is local or widespread. Note that 
during an OSI, such a background samples can be taken after a sample reveals something of possible interest, and does not have to have been taken beforehand as a baseline measurement. This campaign only lasted a few days and had no analysis results before ending. A normal OSI, however, would analyze samples as it acquired them and would likely have the opportunity to collect background samples later if they were needed to better understand a sample result.

\subsection{Logging Sampling/Survey Information}

The sampling and survey team had in their possession a Samsung Galaxy Tab tablet computer for logging purposes. It was evident on the first day that viewing the tablet screen in the sun would be difficult. When the sun was obscured by cloud cover, shade, or at dusk or nighttime (as tested in Mercury, Nevada), viewing the screen was possible without straining the eyes. After the first day, it was decided to not take the tablet computer into the field.

\section{Lesson Learned \#20: The use of the tablet computers for data logging in the field may be difficult in sunny conditions. They were usable during evening hours or significant cloud cover. This is not really something that can be tested "in the lab.” Any tablet computer to be used in the field should be adequately tested in bright sunshine and a workable solution obtained. It is likely this will involve developing some sort of shading mechanism. Such a mechanism should be tested to ensure that in stands up to many days usage in the field.}

\subsection{Conclusions}

In the run-up to the Particulate Release Experiment (PRex), we conducted a survey and sampling campaign on the NNSS at the site of DILUTED WATERS UNE accidental release. The objective of the survey and sampling activities was to test a subset of PRex equipment and sample collection methodologies to gain insight best practices for sampling and survey of a nuclear test site within an OSI framework. A further objective was to determine if there might be useful residual data at old test sites relevant to the development of OSI techniques. Activities included vehicle-based survey, in-situ measurements with HPGe and hand-held $\mathrm{LaBr}_{3}$ systems, soil sampling with a variety of tools, and laboratory gamma spectroscopic analysis of those samples. A further benefit of the measurement campaign was gaining familiarity with the many logistical aspects of performing radiological field work at NNSS ahead of the PRex.

Many practical lessons concerning the proper methodologies and logistics of using the surveying and sampling equipment were noted. These "Lessons Learned" are compiled in Appendix A. The vehiclebased survey was successful in that it found a previously unknown hotspot (identified as ${ }^{232} \mathrm{Th}$ ), even while it was recognized that a better method for keeping a serpentine track without staking was needed. Some of the soil sampling equipment was found to be impractical for the application, and core sampling would not be the correct way to take soil samples for a fresh vent deposit (as opposed to an old site like DiLUTED WATERS). Given the site's age, ${ }^{137}$ Cs was the only fission radioisotope identified, though others were searched for. While not enough samples were taken and analyzed to definitively link the ${ }^{137} \mathrm{Cs}$ to 
PNNL-22494

DILUTED WATERS as opposed to other NNSS activities, results were consistent with the historical DILUTED WATERS plume. MDAs were compared for soil sampling and in situ measurements. 


\subsection{References}

AMS. 2009. AMS: The World's Finest Sampling Equipment. Accessed on 12 February, 2013 at http://www.ams-samplers.com/ (last updated 26 March 2013).

Canberra. 2013a. Apex-Gamma Lab Productivity Suite Suite. Accessed on 12 Feburary, 2013 at http://www.canberra.com/products/radiochemistry_lab/apex-gamma.asp (last updated date not given).

Canberra. 2013b. High-Purity Germanium (HPGe) Detectors. Accessed on 12 February, 2013 at http://www.canberra.com/products/detectors/germanium-detectors.asp (last updated date not given).

Ludlum. 2013. Ludlum Model 711 Radiation Isotope Identifier. Accessed on 12 Feburary, 2013 at http://www.deqtech.com/Ludlum/Products/model711.htm (last updated date not given).

Detwiler, RS, DM Pfund, CE Seifert, and MJ Myjak. 2010. Performance of Airborne Gamma-Ray Spectroscopy Systems for on-Site Inspection under the Comprehensive Nuclear-Test-Ban Treaty. Report No. PNNL-20067, Pacific Northwest National Laboratory, Richland, WA.

Mullen, OW. 1969. Operation Whetstone on-Site Radiological Safety Report. Report No. NVO-162-31, LLNL, Livermore, CA.

Nelson Jr., DJ. 1965. "Report on Diluted Waters Event." Memorandum, U.S. Public Heath Service, Washington, D.C.

Rooney, BD. 2006. Peakeasy v4.26. Los Alamos National Laboratory, Los Alamos, NM

RSI. 2007. RS-700 Mobile Radiation Monitoring System. Accessed on 12 February, 2013 at (last updated date not given).

Schoengold, CR, ME DeMarre, and EM Kirkwood. 1996. Radiological Effluents Released from U.S. Continental Tests 1961 through 1992 (Rev. 1). Report No. DOE/NV-317, United States Department of Energy Nevada Operations.

U.S. Defense Nuclear Agency. 1984. Operations Nougat and Whetstone: Events--Hard Hat, Danny Boy, Marshmallow, Mudpack, Wishbone, Gumdrop, Diluted Water, and Tiny Tot, 15 February 196217 June 1965 Report No. DNA 6320F, U.S. Defense Nuclear Agency, Washington, D.C.

U.S. DOE. 2000. United States Nuclear Tests July 1945 through September 1992 (Rev. 15). Report No. DOE/NV-209, United States Department of Energy Nevada Operations Office, Washington, D.C.

ULINE. No year. Bags. Accessed on 12 February, 2013 at (last updated date not given). 
Wogman, NA, BD Milbrath, R Payne, CE Seifert, JI Friese, HS Miley, TW Bowyer, RC Hanlen, Y Onishi, JC Hayes, MS Wigmosta, and CS Glantz. 2011. A Discussion of Procedures and Equipment for the Comprehensive Nuclear-Test-Ban Treaty on-Site Inspection Environmental Sampling and Analysis. Report No. PNNL-20143, Pacific Northwest National Laboratory, Richland, WA. 


\section{Appendix A: Lessons Learned}

Lesson Learned \#1: Taking coordinates from Google Earth can result in some errors. In a couple of instances, the position indicated on the figure and that indicated by actual GPS coordinates were off by several 10s of meters. This resulted in a quick need for additional approvals, such as pre-activity safety and wildlife surveys, in order to be able to survey in the areas we intended. To mitigate this issue, provide sufficient description of the sampling area where necessary to ensure that the correct locations are marked and that any required pre-activities are performed in the proper areas.

Lessons Learned \#2: When shipping inspection equipment, additional time may be necessary, particularly when equipment containing batteries or radioactive sources may be involved, as these are considered to be hazardous materials. For NNSS, two weeks rather than one week may be necessary.

Lessons Learned \#3: Plan sufficient time for setup, calibration, and daily planning discussions. In particular, any setup time in the field will generally require more time than you expect due to potential complications and plan adjustments. While some future activities will not require as much setup time as the DILUTED WATERS activities, one should expect a minimum of a day in order to setup for future activities. In addition, make sure to add time for field setup of equipment. Even though equipment may be calibrated and tested at the base of operations (Mercury in this case), one still needs setup time to load equipment into trucks and off-road vehicles. This generally took about 20-30 minutes for everything. Be sure to account for this time when planning activities.

Lesson Learned \#4: When performing an off-road vehicle-based survey, the terrain will likely dictate your maximum speed, which will generally be less than $5 \mathrm{mph}(8$ $\mathbf{k m} / \mathbf{h r}$ ). When planning for off-road vehicle survey, do not plan for anything higher than that and do not expect to be able to maintain a constant speed either.

Lesson Learned \#5: Due to the rough conditions off-road in a desert-sagebrush landscape, performing a serpentine pattern with a spacing of $\mathbf{1 0}$ meters is impractical. The minimum possible distance between lines is 15-20 meters. It is unlikely that such a tight spacing would be needed in a CTBT OSI anyway, as the source term from a UNE vent would be more broadly distributed.

Lesson Learned \#6: The operator of the survey detector system should only concentrate on the detector system itself, and not need to multitask by operating multiple pieces of equipment. The RSI detector system, for example, requires enough attention and multitasking itself to warrant the full attention of the operator. In particular, with rough terrain, power to the system can be easily lost and if one is not paying attention to the system, time/data will be lost. 
Lesson Learned \#7: The GPS system associated with the RSI system is sufficiently accurate, to within at least the $30 \mathrm{~m}$ serpentine pattern. In addition, comparison with a higher accuracy GPS system showed that the RSI GPS unit showed only minor differences in position.

Lesson Learned \#8: A GPS Light bar would be preferable for conducting vehicle-based surveys than a handheld GPS unit. Our driver found keeping a straight line while looking at a handheld GPS unit with numerical output to be very difficult - so much so that instead we relied on staked flags to guide him. This necessitated a lot of extra work to put up the stakes that would frankly be better spent on other OSI activities. Also, it is not necessary for an OSI survey to have preciselyspaced coverage as it might be for, as an example, an environmental remediation survey or a survey looking for a point-source. Vented UNEs are broader in extent so that as long as a survey is adequately spaced it would not need the path precision of other types of radiation surveys.

Lesson Learned \#9: The screen brightness on handheld detectors may make them difficult to see in the field due to sunshine. It was often difficult to see the Ludlum 711's screen in the sunshine, preventing the observing of spectra in the field. Evening hour or significant cloud-cover viewing was relatively easy. Our experience is that this is not a problem unique to this model of handheld, and this is not really something that can be tested "in the lab." Any handheld to be used in the field should be adequately tested in bright sunshine and a workable solution obtained.

Lesson Learned \#10: In general, the Lock 'n Load system is not the right tool for collecting samples during an OSI. The total amount of soil (from a single vial) may not be sufficient for any measurements, unless if there is a large concentration of radioactive material within the sample (from near a large release). There are more effective means to collecting soil samples.

Lesson Learned \#11: Split core samplers may be more effective in gathering soil samples than general core samplers. Due to the very fine nature of NNSS soil around DILUTED WATERS, soil particles got trapped between the plastic liner and metal sampler. As a result, the plastic liner containing the soil sample got stuck and we had to use a hand shovel to collect soil. A split core sampler that is hinged will allow one to open the metal sampler and more easily remove the plastic liner.

Lesson Learned \#12: For a new release, where the material is at or very near to the surface, the usefulness of a core sampler is limited. For old sites, assuming the issues in the previous Lesson Learned are addressed, core samplers can be an effective tool for collection soil. However, one may want to use a core sampler at a new release site to obtain some soil composition/background radiation information.

Lesson Learned \#13: A more effective method for obtaining samples while preserving the depth sampled is needed. In particular, a device that allows one to take a soil sample with plates separating each $\mathrm{cm}$ of soil that does not require significant digging 
would be very useful. PNNL has custom-built such systems in the past (Wogman et al. 2011).

Lesson Learned \#14: A simple method to clean the sampling equipment after each collection to avoid potential cross-contamination is needed. This is especially true for more expensive equipment such as core samplers or custom-built soil samplers.

Lesson Learned \#15: An OSI should be prepared for the possibility of spot locations of contamination-level activity, possibly revealed only by alpha or beta measurement. An elevated level of activity may be discovered during an OSI that is inconsistent with the surroundings or expectations, requiring the ability to switch to Contamination Area procedures. In addition, such activity levels may be more noticeable via alpha and beta detection rather than gamma detection. It may be during an OSI that traditional alpha and beta radiation meters used for detecting radiation contamination will detect radiation that gamma survey and spectroscopic methods do not.

Lesson Learned \#16: If samples containing short-lived isotopes are to be analyzed off-site, the procedures need to be worked out in advance. Transferring samples from NNSS to PNNL was slower than expected and would have been problematic had the samples involved short-lived isotopes. Samples were collected into shipping containers (usually small drums) that NNSS had to measure before releasing. PNNL required a measured spectrum of the soil so that it could be determined whether or not to treat the incoming material as radioactive. If so, additional paperwork was needed. Internal shipping personnel were involved at both ends. Though the process could have been streamlined if knowledgeable staff had prioritized the effort, it would still involve some delay. Delay can also happen due to weekend work closure on either end. It should also be noted that though it was not the case for this effort, sometimes the shipment of soil itself can be problematic and subject to quarantines.

Lesson Learned \#17: It is important when collecting samples to try to locate areas that are pristine and do not appear to have been modified after the event. This was very difficult to determine at a 50 year-old site but may be easier at a newer site. It may be best not to take samples as close as possible to a site, if there are indications that people or vehicles were disturbing the soil, but rather locate a spot nearby where there was no such disturbance.

Lesson Learned \#18: The best place to sample a crater, is likely not the crater itself. Usually a crater is formed in the process that ends the vent, or sometime afterward. Thus the soil at the top of a crater may in fact be new-surface soil first exposed during the collapse rather than soil contaminated by a vent.

Lesson Learned \#19: Background samples are a necessary part of an OSI. They provide a basis of comparison for determining if something seen in a sample is local or widespread. Note that during an OSI such a background sample can be taken after a sample reveals something of possible interest, and does not have to have 
been taken beforehand as a baseline measurement. This campaign only lasted a few days and had no analysis results before ending. A normal OSI, however, would have been analyzing samples as it acquired them and would likely have the opportunity to collect background samples later if they were needed to better understand a sample result.

Lesson Learned \#20: The use of the tablet computers for data logging in the field may be difficult in sunny conditions. They were usable during evening hours or significant cloud cover. This is not really something that can be tested "in the lab.” Any tablet computer to be used in the field should be adequately tested in bright sunshine and a workable solution obtained. It is likely this will involve developing some sort of shading mechanism. Such a mechanism should be tested to ensure that in stands up to many days usage in the field. 



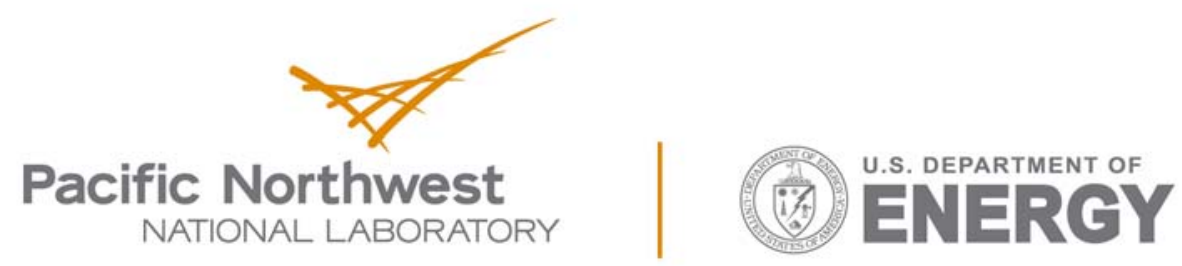

Proudly Operated by Battelle Since 1965

902 Battelle Boulevard

P.O. Box 999

Richland, WA 99352

1-888-375-PNNL (7665)

www.pnnl.gov 